\title{
Spatiotemporal Differences in Dominants of Dryness/Wetness Changes in Southwest China
}

\author{
Shujia Zhou $\mathbb{D}^{1},{ }^{1}$ Shanlei Sun $\left(\mathbb{D},{ }^{1}\right.$ Wanrong Shi, ${ }^{1}$ Jiazhi Wang, ${ }^{1}$ Jinjian Li, ${ }^{2}$ Guojie Wang, ${ }^{3}$ \\ and Weiping Lou ${ }^{4}$ \\ ${ }^{1}$ Collaborative Innovation Center on Forecast and Evaluation of Meteorological Disasters/Key Laboratory of \\ Meteorological Disaster, Ministry of Education/International Joint Research Laboratory on Climate and Environment Change, \\ Nanjing University of Information Science and Technology (NUIST), Nanjing, China \\ ${ }^{2}$ School of Atmospheric Sciences, Chengdu University of Information Technology, Chengdu, China \\ ${ }^{3}$ School of Geography Sciences, NUIST, Nanjing, China \\ ${ }^{4}$ Xinchang County Meteorological Bureau, Shaoxing, China
}

Correspondence should be addressed to Shanlei Sun; sun.s@nuist.edu.cn

Received 4 August 2019; Accepted 11 September 2019; Published 9 October 2019

Academic Editor: Marina Baldi

Copyright (c) 2019 Shujia Zhou et al. This is an open access article distributed under the Creative Commons Attribution License, which permits unrestricted use, distribution, and reproduction in any medium, provided the original work is properly cited.

A full analysis of 3-month Standardized Precipitation-Evapotranspiration index (SPEI-3) changes and attribution analyses are of significance for deeply understanding dryness/wetness evolutions and thus formulating specific measures to sustain regional development. In this study, we analyze monthly and annual SPEI-3 changes over Southwest China (SWC; including Sichuan (SC), Chongqing (CQ), Guizhou (GZ), Yunnan (YN), and west Guangxi (wGX)) during 1961-2012, using the SPEI model and routine meteorological measurements at 269 weather sites. For SWC and each subregion (excluding wGX), annual SPEI-3 during 1961-2012 tends to decrease, and drying is at most of months in January and September-December, but wetting is in February-August (excluding March for wGX). Additionally, more than 50\% of sites show declined and increased SPEI-3 in January, April, June, and August-December and the remaining months, respectively. Except for wGX with dominant of $\mathrm{ET}_{0}$, annual SPEI-3 changes in SWC and other four subregions have dominant of precipitation. Spatially, annual SPEI-3 changes at $59 \%$ of sites are because of precipitation, generally located in southeast SC, south YN, CQ, GZ, and south and northeast wGX. Nevertheless, dominants at regional and site scales vary among months, e.g., SWC, SC, CQ, and GZ, having dominant of precipitation $\left(\mathrm{ET}_{0}\right)$ during September-December (most of months during January-August), YN always with dominant of precipitation, and wGX with dominant of precipitation $\left(\mathrm{ET}_{0}\right)$ in February-April and July-December (January, May, and June). Importantly, this study provides a reference for quantitatively evaluating spatiotemporal dryness/wetness variations with climate change, especially for regions with significant drying/wetting.

\section{Introduction}

Drought is usually regarded as one of the most damaging natural hazards [1], mainly due to its far-reaching impacts on nature and socioeconomic systems [2]. With the exacerbation of climate change, drought (e.g., intensity, frequency, duration, and spatial extent) have intensified across China, especially in Southwest China (SWC), with increasing occurrences and strengthening intensity [3-6], e.g., SWC droughts in the autumn of 2003 and during
2009/2010. Therefore, their negative impacts are increasing and will continue in future [4, 5, 7-9]. Taking the 2009/ 2010 SWC drought as an example, approximately 21 million people were short of drinking water, and economic losses reached nearly $\$ 30$ billion [4-6]. Thus, to investigate dryness/wetness (or drought) changes and relevant mechanisms has become an imperative issue, which favors better understanding of dry/wet (or drought) processes and thus improving the drought monitoring and forecasting capability. 
Because of drought complexity and much limited observations, to directly conduct drought analyses is difficult. Therefore, a number of drought indices have been developed to characterize drought evolutions [1013]. Commonly, these indices are of two types: precipitation-based one (e.g., Relative Humidity Index and Standardized Precipitation Index (SPI)) and integrated one (involved precipitation and potential (PET) or reference evapotranspiration $\left(\mathrm{ET}_{0}\right)$; e.g., Palmer Drought Severity Index (PDSI) and Standardized PrecipitationEvapotranspiration Index (SPEI)). Drought is a specific phenomenon of water budget, namely, water deficit, and characterized by below-normal water availability over a period from several months to a few decades $[14,15]$; thus, its evolution is always closely associated with water supply (e.g., precipitation) and demand (e.g., evapotranspiration, partly reflected by $\left.\mathrm{PET}_{\text {or }} \mathrm{ET}_{0}\right)[16,17]$. So, the precipitation-based drought indices without considerations of evapotranspiration, PET or $\mathrm{ET}_{0}$ impacts, can introduce biases for comprehensively understanding drought mechanisms, which has been confirmed by scholars in recent years [17-20]. Additionally, in response to climate change (e.g., temperature, wind speed, sunshine duration or net radiation, and relative humidity [21-24]), changed evapotranspiration and PET or $\mathrm{ET}_{0}$ have been detected extensively over the world [21, 25-27] and thus impact drought to some extent [17, 19, 20, 28]. Just because of these, increasing studies have analyzed drought characteristics in different regions using the integrated drought indices (such as PDSI and SPEI) [29-31]. Specially, due to the superiority including more physical-based considerations (e.g., PET or $\mathrm{ET}_{0}$ is involved), capability to monitor multiscalar drought (e.g., 3- and 12-months) and simple computations, the SPEI has been widely applied to monitor and evaluate dry/wet conditions and droughts over China since it was proposed [6, 32-35].

Reviewing the previous studies, there is a general agreement that SWC is becoming drier with more frequent and higher intense droughts during the past five decades $[9,17,36,37]$, and drought severity will be further strengthened in future $[7,8,38]$. To aim at this issue, scholars have tried to reveal its underlying causes from different perspectives, e.g., negative precipitation anomalies based on atmospheric dynamics [6, 39-42]. Undoubtedly, these studies provided helpful information to cognize the drying conditions and the intensifying droughts over SWC; however, two major gaps remain. Firstly, roles of atmospheric evaporative demand (reflected by PET or $\mathrm{ET}_{0}$ ) and even its driving factors (i.e., temperature, sunshine duration, relative humidity, and wind speed) in the ongoing drying are rarely focused in SWC, in spite of its closer relationship with dryness/wetness $[19,20,29,43]$. It is reported that obvious changes in various climate variables and then $\mathrm{ET}_{0}$ have been widely observed over SWC [17, 44-46]. Secondly, more researches are concern of decadal, annual, and seasonal dryness/ wetness changes in SWC, while less attention is paid on monthly variations. In practice, quantitative knowledge on climate change influences in monthly dryness/wetness is more important to plan water resources and thus formulate counter measures for agricultural managements and water supply, especially for SWC under the intensified droughts.

To fill these gaps, we have quantitatively assessed precipitation and $\mathrm{ET}_{0}$ impacts on annual and monthly dryness/ wetness (reflected by 3-month SPEI (SPEI-3)) changes at regional and site scales during 1961-2012 over SWC. Therefore, this study aims to (1) analyze precipitation, FAO (Food and Agriculture Organization)-56 PenmanMonteith $\mathrm{ET}_{0}$ and SPEI-3 variations on different spatiotemporal scales and (2) then identify dominants of SPEI-3 changes based on individual contributions of precipitation and $\mathrm{ET}_{0}$, which are separated by a method from Sun et al. [47]. This study will provide a significant insight, allowing us to fully understand the spatiotemporal variations of SPEI-3 with climate change and improve drought monitoring and forecasting capability with the detailed and quantitative reference information.

\section{Data and Methodology}

2.1. Study Region and Data. Here, we specify SWC between $21-34^{\circ} \mathrm{N}$ and $97-110^{\circ} \mathrm{E}$ (Figure 1), including Sichuan (SC), Chongqing (CQ), Guizhou (GZ), Yunnan (YN), and west Guangxi (wGX). SWC is characterized by complex terrain, and its elevation decreases from northwest to southeast (Figure 1). This region contains the headwaters of Yangtze River, Mekong River, and Pearl River. A typical subtropical monsoon climate prevails across SWC, with a clearly defined dry/wet season. Generally, SWC regional mean monthly precipitation increases quickly from April, peaks at July and sharply decreases afterward.

For running the FAO-56 Penman-Monteith equation and the SPEI model, a monthly meteorological dataset during 1960-2012, including precipitation (mm), mean, maximum and minimum air temperatures $\left({ }^{\circ} \mathrm{C}\right)$, wind speed at 10 meter $(\mathrm{m} / \mathrm{s})$, sunshine duration $(\mathrm{h} / \mathrm{mon})$ and relative humidity (\%), was collected from 334 weather sites of the China Metrological Administration (CMA). Before using, two data quality issues, i.e., inhomogeneity caused by nonclimatic factors (e.g., changes in instruments, station locations, and environment around observation field) and missing values, should be solved. For simplicity, we will not show the detailed procedures to process these two issues, but more information can be found in Sun et al. [17]. Lastly, the 269 sites are selected (Figure 1).

\subsection{Methodology}

2.2.1. Temporal Trends of Hydroclimatic Variables. Trend of each hydroclimatic variable can be obtained using

$$
y=a \cdot x+b, \quad x=1,2, \ldots, n
$$

where $y, a, b$, and $x$ represent the fitted value of the variable, temporal trend, intercept, and year, respectively and $n$ is the sample size. Here, the regression parameters are estimated 


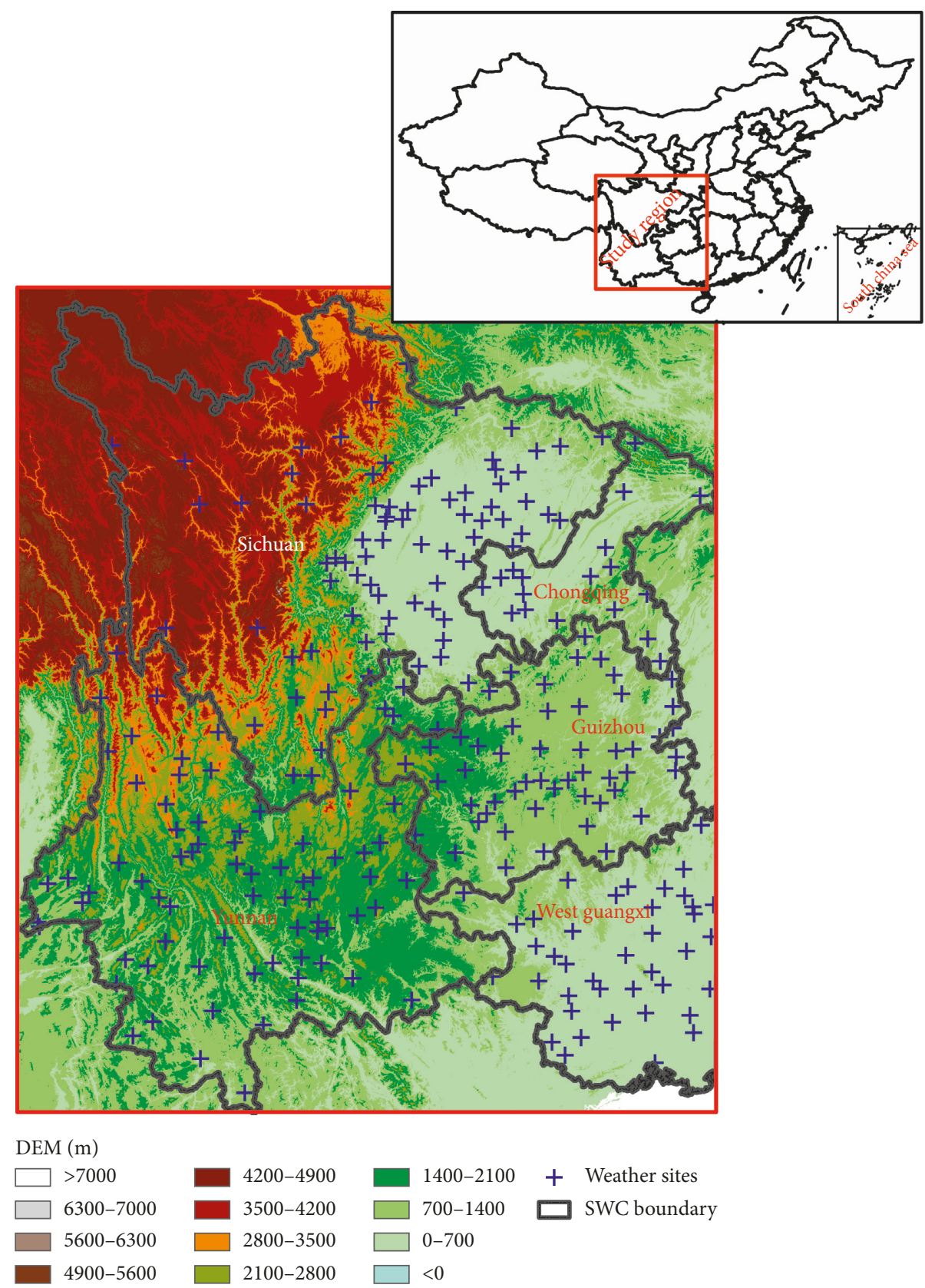

FIGURE 1: Location of 269 weather sites over SWC. The shading indicates elevation, which is represented with DEM (Digital Elevation Model; http://srtm.csi.cgiar.org/) with a spatial resolution of $90 \mathrm{~m} \times 90 \mathrm{~m}$.

based on the least squares technique. A positive (negative) value of $a$ suggests an increasing (decreasing) trend. A larger $a$ denotes a stronger trend of $y$. To test whether the linear trend is significantly ( $p>0.05$ here) different from zero, Student's $t$ significance test is performed.

2.2.2. FAO-56 Penman-Monteith Equation. Considering our major objectives to quantify climate change impacts on SPEI-3, the selected $\mathrm{ET}_{0}$ equation should involve a comprehensive physical concept of evapotranspiration processes. Therefore, the FAO-56 Penman-Monteith equation [48] is used here, i.e.,

$$
\mathrm{ET}_{0}=\frac{0.408 \cdot \Delta \cdot(\mathrm{Rn}-G)+\gamma \cdot(900 /(\text { Tave }+273)) \cdot \mathrm{Wnd} \cdot \mathrm{Vpd}}{\Delta+\gamma \cdot(1+0.34 \cdot \mathrm{Wnd})},
$$

where $\mathrm{Rn}\left(\mathrm{MJ} /\left(\mathrm{m}^{2}\right.\right.$ mon $\left.)\right)$ is the difference between incoming net shortwave and outgoing net longwave radiation; $G\left(\mathrm{MJ} /\left(\mathrm{m}^{2} \mathrm{mon}\right)\right)$ denotes the soil heat flux and is neglected on monthly scale; $\gamma\left(\mathrm{kPa} /{ }^{\circ} \mathrm{C}\right)$ and $\Delta\left(\mathrm{kPa} /{ }^{\circ} \mathrm{C}\right)$ are the psychrometric constant and slope vapor pressure curve, respectively; and Wnd $(\mathrm{m} / \mathrm{s})$ is 2-meter wind speed, transferred from 10 -meter wind speed. $\mathrm{Vpd}\left(\mathrm{kPa} /{ }^{\circ} \mathrm{C}\right)$ represents the vapor pressure deficit (saturation minus actual vapor pressure), and Tave $\left({ }^{\circ} \mathrm{C}\right)$ is the mean temperature. 
Notably, because of limited Rn observations, we followed Allen et al. [48] and estimated its monthly value at each site based on measured sunshine duration (see Text S1).

\subsubsection{Standardized Precipitation-Evapotranspiration Index.} Since the SPEI is proposed by Vicente-Serrano et al. [12], its capability in representing dry/wet conditions or droughts has been widely validated over the globe. Wang and Chen stated that it could well reproduce the principal drought characteristics over SWC compared against drought statistics from various yearbooks of metrological disasters [36]. For computing SPEI, difference between precipitation and $\mathrm{ET}_{0}\left(P-\mathrm{ET}_{0}\right)$ is firstly calculated to represent the climatic water balance $(D)$ at a certain month. Then, the $D$ is aggregated at various time scales (e.g., 3 and 12 months). For best fitting the $D$ time series at each month, a threeparameter log-logistic distribution model is recommended, and then an inverse normal function is employed to standardize the probabilities [12]. Usually, over a region, negative and positive SPEI implies dry and wet, respectively. The larger the absolute value of SPEI is, the drier or wetter this region becomes. More information about the SPEI computations and the thresholds of drought at different levels can be found in reference [12]. Additionally, this study focuses on the short- and medium-term dryness/ wetness, which are closely related to agricultural droughts (can be reflected by soil moisture anomalies). In the preliminary work (not shown here), we have computed the monthly correlation coefficients between the 1-, 3-, 6-, 9and 12-month SPEI and the soil moisture from the Noah model of Global Land Data Assimilation System (version 2.0; https://disc.gsfc.nasa.gov) over SWC. The results stated that the SPEI-3 show the largest correlation coefficient, implying that the SPEI- 3 can best reflect dry/wet conditions over SWC. As a result, the SPEI-3 was chosen here for further analyses. Monthly SPEI-3 time series during 1961-2012 are calculated at 269 sites, and then annual SPEI-3 are obtained by averaging monthly values during each year.

2.2.4. Respective Contributions of Precipitation and $E T_{0}$. The SPEI is a function of precipitation and driving factors of $\mathrm{ET}_{0}$. Then, interactions among these factors potentially bias contributions of each factor to SPEI changes and finally influence conclusions $[49,50]$. For eliminating compound effects, Sun et al. [47] proposed a separation method and validated it over Poyang Lake Basin, China, which showed that relative to other methods, this method had higher accuracy and efficiency. Hereby, it is chosen to separate contributions from each factor alone to monthly and annual SPEI-3 changes. Firstly, six (one control and five sensitivity) experiments are performed with the SPEI model (Table 1). The control experiment (SPEI_CTR) is conducted using the original time series (i.e., remaining intra- and interannual fluctuations) of each driving factor during 1960-2012 as inputs. However, a sensitivity experiment (i.e., SPEI_x) is run with inputs of the 52-year (1961-2012) mean monthly values of $x$ factor and original time series of other factors in
TABLE 1: Detailed information about numerical experiments.

\begin{tabular}{|c|c|}
\hline Experiments & Inputs \\
\hline SPEI_CTR & $\begin{array}{l}\text { Monthly precipitation, Rn, Tave, Wnd, and Vpd } \\
\text { during } 1960-2012\end{array}$ \\
\hline SPEI_P & $\begin{array}{c}\text { Monthly precipitation fixed at 52-year (1961-2012) } \\
\text { mean; monthly Rn, Tave, Wnd, and Vpd during } \\
\text { 1960-2012 }\end{array}$ \\
\hline SPEI_Rn & $\begin{array}{l}\text { Monthly Rn fixed at 52-year monthly mean; } \\
\text { monthly precipitation, Tave, Wnd, and Vpd during } \\
\text { 1960-2012 }\end{array}$ \\
\hline SPEI_Tave & $\begin{array}{l}\text { Monthly Tave fixed at 52-year monthly mean; } \\
\text { monthly Rn, precipitation, Wnd, and Vpd during } \\
\text { 1960-2012 }\end{array}$ \\
\hline SPEI_Wnd & $\begin{array}{c}\text { Monthly Wnd fixed at 52-year monthly mean; } \\
\text { monthly Rn, Tave, precipitation, and Vpd during } \\
1960-2012\end{array}$ \\
\hline SPEI_Vpd & $\begin{array}{l}\text { Monthly Vpd fixed at 52-year monthly mean; } \\
\text { monthly Rn, Tave, Wnd, and precipitation during } \\
1960-2012\end{array}$ \\
\hline
\end{tabular}

1960-2012. Taking sensitivity experiment of precipitation (namely, SPEI_P) as an example, inputs include the 52-year mean monthly precipitation and the 1960-2012 monthly Tave, Rn, Vpd, and Wnd. Then, equations are established based on a hypothesis that the SPEI_x SPEI-3 changes are induced by factors except for $x$ [47], such as

$$
\sum_{k \neq i}^{n} C_{k}=T^{\text {SPEI } \_i}
$$

where $C_{k}$ indicates contribution of $k$ factor alone to SPEI-3 trends; $\sum_{k \neq i}^{n} C_{k}$ is the summed contributions from all factors except for $i$ factor; $n$ ( $=5$ here) represents number of factors; and $T^{\text {SPEI } ~} i$ denotes the SPEI_ $i$ SPEI-3 trends. Solving equation (2), each factor alone contribution is represented as

$$
C_{k}=\frac{\sum_{i \neq k}^{n} T^{\mathrm{SPEI} \_i}-(n-2) \cdot T^{\mathrm{SPEI} \_i}}{n-1} .
$$

This approach will be conducted at each site and each year. Note that $\mathrm{ET}_{0}$ contributions to annual and monthly SPEI-3 trends are sum of respective contributions of $\mathrm{Rn}$, Tave, Vpd, and Wnd.

\section{Results}

\subsection{Precipitation and $E T_{O}$ Changes}

3.1.1. Precipitation Changes. During the past 52 years, annual precipitation for SWC and all subregions consistently decreases with a range from $-2.16 \mathrm{~mm} / \mathrm{yr}$ to $-0.82 \mathrm{~mm} / \mathrm{yr}$ (the right panel of Figure 2(a)), of which SC, GZ, and SWC trends are significant. During January-July (excluding April with a significant decrease), SWC precipitation increases by $<0.25 \mathrm{~mm} / \mathrm{yr}$ (the left panel of Figure 2(a)), but decreases in August-December, especially for August having a maximum rate of $-0.84 \mathrm{~mm} / \mathrm{yr}$. Among 60 cases $(12$ months $\times 5$ subregions; the left panel of Figure 2(a)), 35 of them with declined precipitation generally occur in April and August-December, but the remaining cases correspond to 


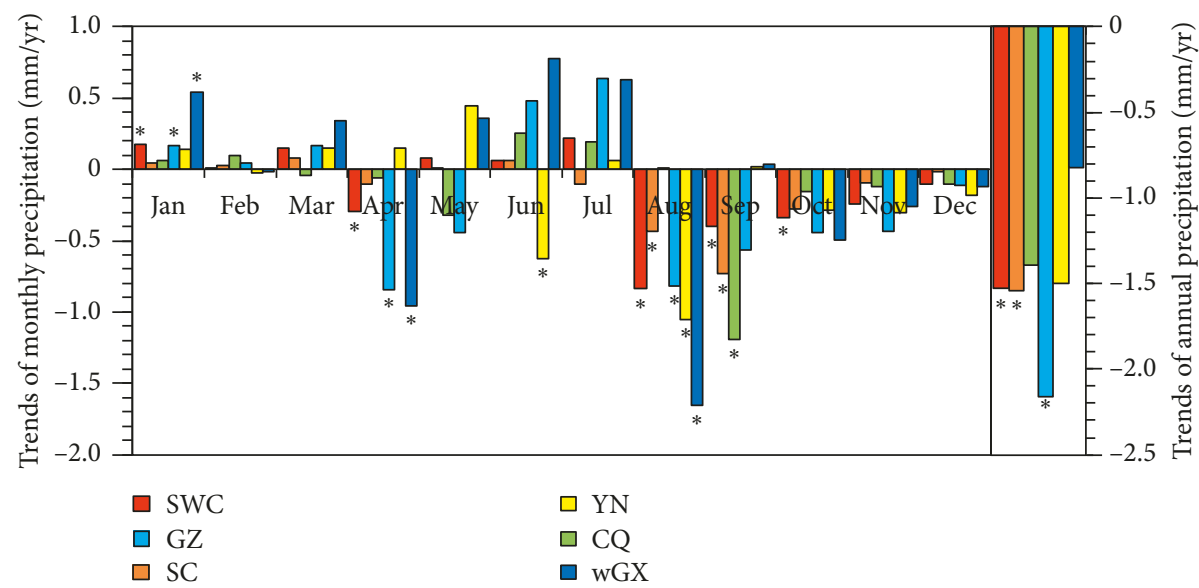

(a)

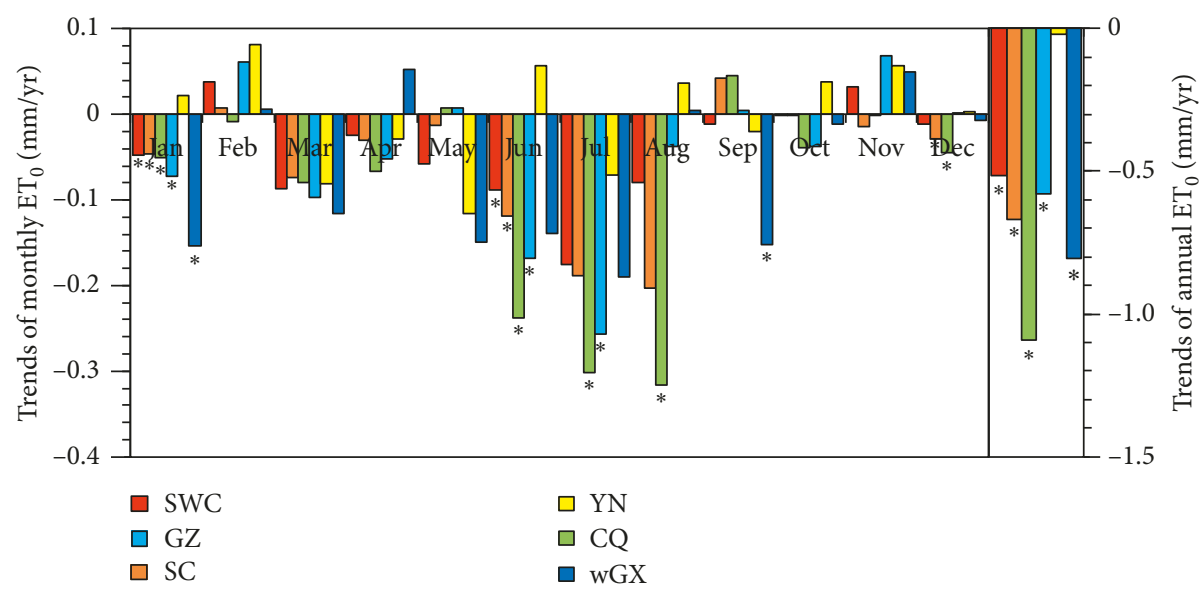

(b)

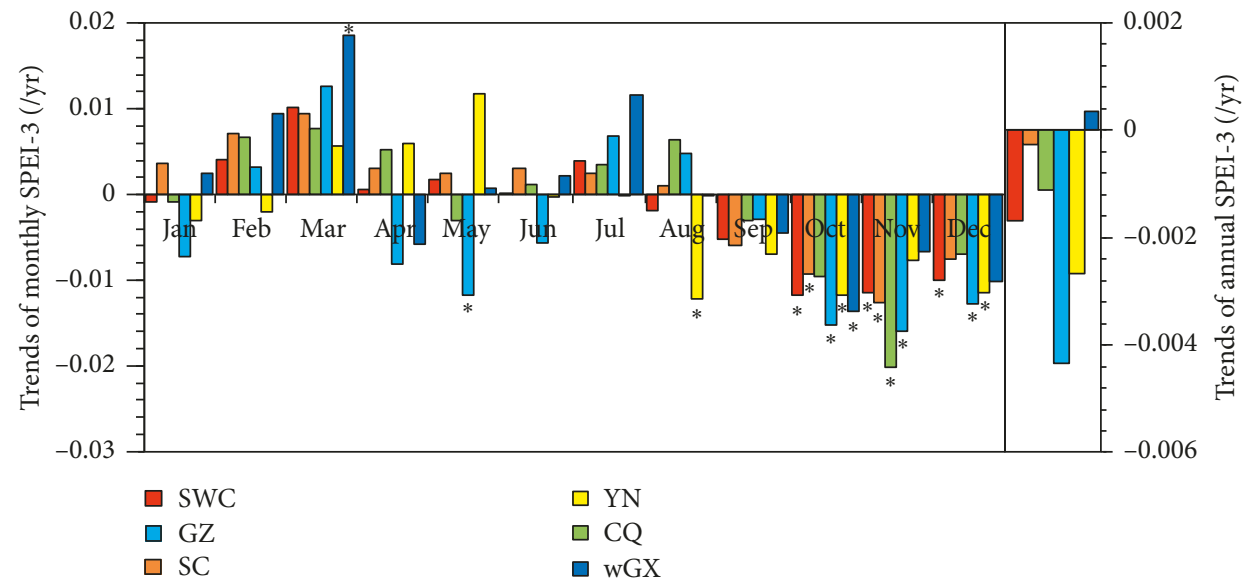

(c)

FIGURE 2: Monthly and annual trends of regional mean precipitation, $\mathrm{ET}_{0}$, and SPEI-3 during 1961-2012. The asterisk denotes that trend is significant.

smaller increases basically during January-March, June, and July.

Seen from Table 2 and Figure 3(a1), sites with decreased annual precipitation are extensively distributed across SWC, accounting for $82.5 \%$ of sites, and $23.5 \%$ of sites with significant and larger $(<-2.1 \mathrm{~mm} / \mathrm{yr})$ decreases are mostly located in southeast SC, mid-east YN, and north GZ. During January-July (excluding April), there exist $>50 \%$ of sites showing increased precipitation, especially for January and March with a site percentage $>85 \%$. By contrast, precipitation at $>70 \%$ of sites are observed to decrease in April and August-December, of which August and November 
TABLE 2: Site percentage (\%) with increased and decreased precipitation/ $\mathrm{ET}_{0} / \mathrm{SPEI}-3$.

\begin{tabular}{|c|c|c|c|c|c|c|c|c|c|c|c|c|c|c|}
\hline & & Annual & Jan & Feb & Mar & Apr & May & Jun & Jul & Aug & Sep & Oct & Nov & Dec \\
\hline \multirow{4}{*}{ Precipitation } & SI & 1.1 & 25.0 & 1.9 & 9.3 & 5.6 & 6.3 & 9.0 & 4.5 & 0 & 1.1 & 1.9 & 0.4 & 0 \\
\hline & II & 16.4 & 64.6 & 55.2 & 76.1 & 33.6 & 51.5 & 43.7 & 61.2 & 14.2 & 26.5 & 16.4 & 14.6 & 17.5 \\
\hline & SD & 23.5 & 0 & 0 & 0.4 & 26.5 & 3.4 & 6.7 & 3.4 & 28.7 & 18.3 & 16.4 & 12.7 & 5.6 \\
\hline & ID & 59.0 & 10.4 & 42.9 & 14.2 & 34.3 & 38.8 & 40.7 & 31.0 & 57.1 & 54.1 & 65.3 & 72.4 & 76.9 \\
\hline \multirow{4}{*}{$\mathrm{ET}_{0}$} & SI & 11.6 & 9.0 & 13.8 & 1.9 & 7.5 & 1.9 & 6.0 & 1.1 & 6.7 & 6.3 & 7.5 & 25.7 & 10.8 \\
\hline & II & 18.7 & 15.7 & 53.0 & 15.7 & 36.9 & 41.0 & 22.8 & 12.3 & 31.3 & 42.2 & 44.8 & 41.4 & 28.0 \\
\hline & SD & 42.9 & 46.6 & 3.4 & 22.8 & 11.9 & 14.9 & 31.0 & 46.6 & 19.8 & 11.6 & 10.1 & 8.2 & 23.1 \\
\hline & ID & 26.9 & 28.7 & 29.9 & 59.7 & 43.7 & 42.2 & 40.3 & 39.9 & 42.2 & 39.9 & 37.7 & 24.6 & 38.1 \\
\hline \multirow{4}{*}{ SPEI-3 } & SI & 4.9 & 5.2 & 8.2 & 25.7 & 10.4 & 9.7 & 4.9 & 10.1 & 5.2 & 0 & 0 & 0 & 2.2 \\
\hline & II & 30.2 & 38.1 & 59.7 & 62.7 & 38.4 & 45.5 & 42.9 & 54.5 & 38.4 & 23.1 & 6.3 & 12.7 & 8.2 \\
\hline & SD & 11.9 & 4.1 & 2.2 & 0.4 & 7.8 & 7.5 & 2.2 & 1.5 & 10.1 & 8.6 & 28.7 & 34.3 & 29.5 \\
\hline & ID & 53.0 & 52.6 & 29.9 & 11.2 & 43.3 & 37.3 & 50.0 & 34.0 & 46.3 & 68.3 & 64.9 & 53.0 & 60.1 \\
\hline
\end{tabular}

Note: SI (SD) suggests that increasing (decreasing) trend is significant, while II (ID) represents that increasing (decreasing) trend is insignificant.
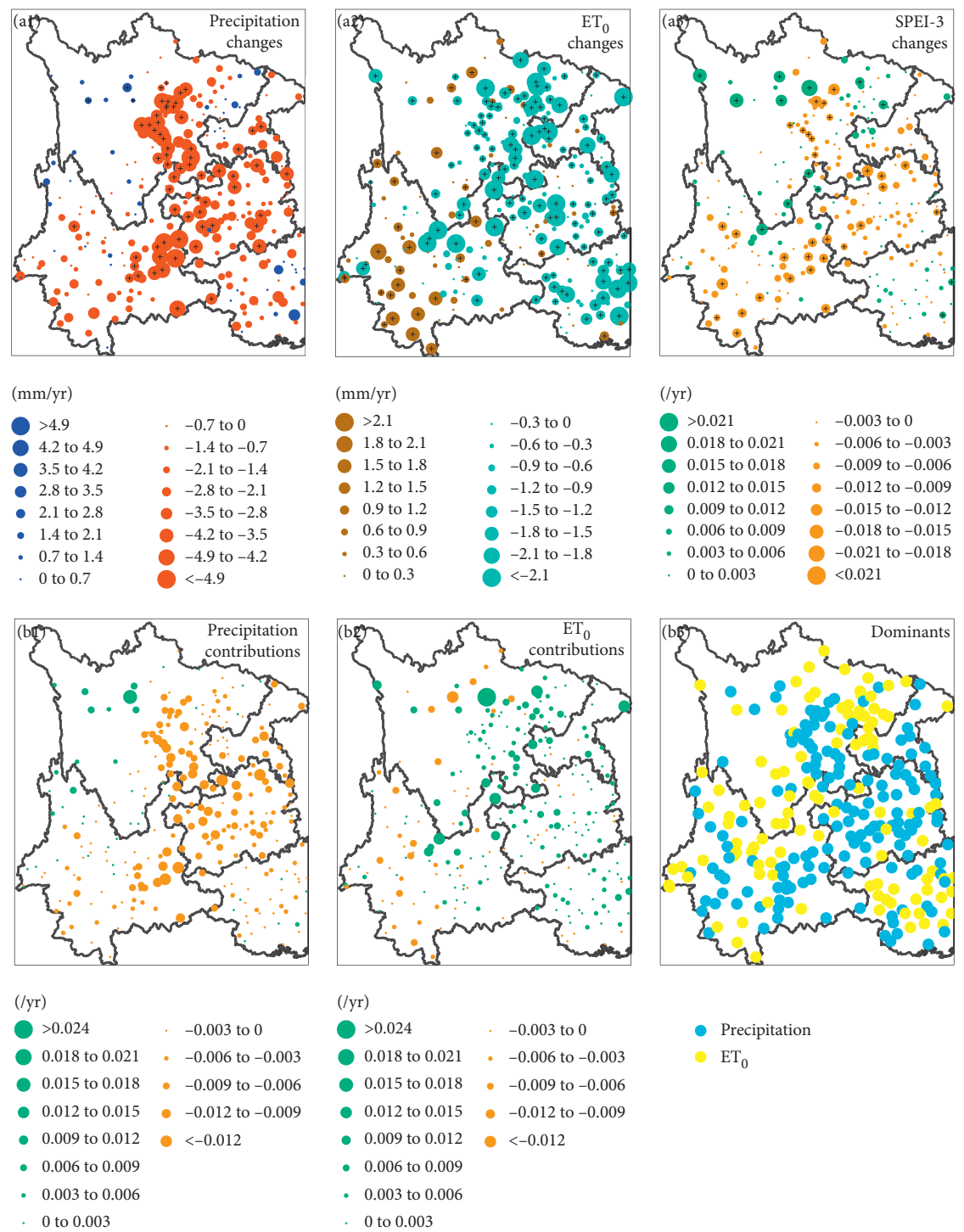

FIgURE 3: Annual spatial distributions of precipitation, $\mathrm{ET}_{0}$, and SPEI-3 changes (a1-3) and precipitation and $\mathrm{ET}_{0}$ alone contributions to SPEI-3 trends (b1-2) with dominants (b3) during 1961-2012. The plus sign denotes that trend is significant.

correspond to the largest site percentage of around $85 \%$. Regarding significantly increased precipitation, its site percentage in January is $25 \%$, while percentages of other months are all $<10 \%$ and even those of August and December are equal to 0 . For site percentages with significant precipitation decreases, five months correspond to a site 
percentage of $>10 \%$, particularly for April and August with the maxima of $>26 \%$; however, other seven months have a percentage between 0 and $7 \%$. Moreover, we have plotted spatial distributions of monthly precipitation changes during 1961-2012 (Figures S1(a1-a12)), generally suggesting that monthly spatial patterns exhibit obvious intra-annual differences, and detailed descriptions are presented in Text S2.

3.1.2. $E T_{0}$ Changes. For SWC, annual $\mathrm{ET}_{0}$ significantly decreases by $0.55 \mathrm{~mm} / \mathrm{yr}$ during 1961-2012 (the right panel of Figure 2(b)). Except for $\mathrm{YN}$, annual $\mathrm{ET}_{0}$ has a significant reduction of $<-0.6 \mathrm{~mm} / \mathrm{yr}$ in other subregions, of which a maxima $(-1.07 \mathrm{~mm} / \mathrm{yr})$ occurs in CQ. SWC ET ${ }_{0}$ decreases at 10 months (January and June with significant reduction), especially for July with a largest rate of $0.18 \mathrm{~mm} / \mathrm{yr}$, but a slight increase happens in February and November. For all cases (12 months $\times 5$ subregions; the left panel of Figure 2(b)), there are 42 cases (13 cases with significant reduction) with decreased monthly $\mathrm{ET}_{0}$, following by a larger decrease for each subregion generally during March and June-August. Moreover, it should be noted that for each subregion (excluding $\mathrm{YN})$, most $(\geq 8)$ of months show decreased $\mathrm{ET}_{0}$.

Overall, sites with significant changes in annual $\mathrm{ET}_{0}$ are widespread across SWC, accounting for $54.5 \%$ of sites (Table 2 and Figure 3(a2)). In detail, 69.8\% (30.2\%) of sites with decreased (increased) $\mathrm{ET}_{0}$ is largely located in east $\mathrm{SWC}$ and $\mathrm{YN}$ (west $\mathrm{YN}$ and west $\mathrm{SC}$ ), and a larger rate $(>1.5 \mathrm{~mm} /$ yr) basically exists in southwest YN, northwest GZ, and east wGX and SC (Figure 3(a2)). In Table 2, monthly $\mathrm{ET}_{0}$ at $>50 \%$ of sites increases (decreases) during February, October, and November (other months). Moreover, site percentages corresponding to significant $\mathrm{ET}_{0}$ increases are $>10 \%$ in February, November, and December, while other months have a percentage of $<10 \%$. Differently, except for February and November, $\mathrm{ET}_{0}$ at $>10 \%$ sites show a significant reduction in the remaining months, of which the maximum site percentage (close to 50\%) appears in January and July. Regarding spatial distributions of monthly $\mathrm{ET}_{0}$ changes, there is not a consistent pattern among months (Figures S2(b1-b12)), and detailed information are presented in Text S2.

3.2. SPEI-3 Dryness/Wetness Changes. Taking SWC as a whole (right panel of Figure 2(c)), annual SPEI-3 decreases by $0.0017 / y r$ during 1961-2012, implying that SWC has became drying. Except for wGX with a slight increase in SPEI-3, other subregions have been drier with a rate between $0.0003 / \mathrm{yr}$ and $0.0043 / \mathrm{yr}$ (the right panel of Figure 2(c)). In January and August-December (the left panel of Figure 2(c)), SWC SPEI-3 differently declines, of which trends during October-December are significant and $<-0.01 / y r$. By contrast, SWC SPEI-3 trends in February-July are positive but insignificant. Similarly for each subregion, SPEI- 3 changes also exhibit evident intra-annual differences, followed by about a half of cases ( 12 months $\times 5$ subregions) with decreasing trends. Over each subregion, a downward
SPEI-3 trend mainly occurs in January and SeptemberDecember and is generally significant in OctoberNovember. However, SPEI-3 trends in most of months during February-August are positive and insignificant.

Table 2 illustrates that despite $64.9 \%$ of sites with decreased annual SPEI-3, there are only $11.9 \%$ of sites with significant trends, and mid-east and south $\mathrm{YN}$, mid-north SC, and northeast GZ have a larger decrease $(<-0.012 / \mathrm{yr}$; Figure 3(a3)). Besides, annual SPEI-3 increases at $35.1 \%$ of sites, generally covering over SC (excluding southeast part), middle-north YN, and wGX (Figure 3(a3)). On monthly scale, eight months correspond to decreased SEPI-3 with a site percentage of $>50 \%$, particularly in October-December with a larger value of $>85 \%$ ( $>25 \%$ of sites with significant trends), while in February, March, May, and July, $>50 \%$ of sites show increased SPEI-3. In January (Figure 4(a)), sites with positive (negative) SPEI-3 trends largely appear in north SWC, north YN, and wGX (south YN and GZ), where sites in north SC (southmost YN) have the largest and significant changes with an absolute value $>0.018 / y$. Generally, the February SPEI-3 decreases in west SWC and part of GZ, especially for sites in south YN with a maximum decrease $(<-0.021 / \mathrm{yr}$ to be significant), whereas it increases in east SWC (excluding part of GZ) and mid-north YN and shows the largest increasing rate $(>0.021 / \mathrm{yr}$ to be significant) in northeast SC (Figure 4(b)). In March (Figure 4(c)), except for $<11.6 \%$ of sites having decreased SPEI-3 in west SWC, SPEI- 3 consistently increases across SWC but with different rates, and meanwhile east SC, southeast GZ, and wGX indicate significant and larger trends $(>0.018 / \mathrm{yr})$, approximately accounting for $25.7 \%$ of sites. In contrast to February, spatial distribution of SPEI-3 changes in April are mainly characterized by upward trends in west SWC (excluding northwest YN) and juncture of SC and CQ but downward ones in the remaining regions, followed by significant changes with a rate of $>0.018 / y r$ generally in north SC, juncture of SC and CQ, most of GZ, and mid-north and southwest YN (Figure 4(d)). For May (Figure 4(e)), SPEI-3 trends are basically positive (negative) in northeast SWC (other regions), of which around 7.5\% (9.7\%) of sites in GZ (northeast SC and west $\mathrm{YN}$ ) show a significant and larger changing rate of $>0.018 / \mathrm{yr}$. In June (Figure $4(\mathrm{f})$ ), there is a complex spatial distribution for SPEI-3 changes, whose magnitudes are $<0.012 / \mathrm{yr}$. During July (Figure $4(\mathrm{~g})$ ), increased SPEI- 3 is widely distributed across east SWC, of which about $10.1 \%$ of sites with a significant and larger rate $(>0.015 / \mathrm{yr})$ are located in northeast SC, southwest GZ, and east wGX; however, a mixed spatial distribution exists in west SWC, i.e., negative and positive SPEI-3 trends in middle SC and YN (excluding mid-north part), and west SC and mid-north YN, respectively. Figure 4(h) suggests that the August SPEI-3 mostly increases (decreases) by different rates in northeast SWC, west SC, and east wGX (middle SC, YN, and west wGX), particularly in northeast SC (YN and part of SC) with a significant and larger trend of $>0.018 / \mathrm{yr}$ $(<-0.015 / y r)$. During September (Figure 4(i)), sites with decreased SPEI-3 are widely distributed, accounting for $76.9 \%$ of sites, and significant and larger decreases (<-0.015/ yr) mainly appear in middle SWC. Generally, SPEI-3 


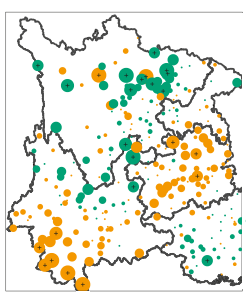

(a) Jan

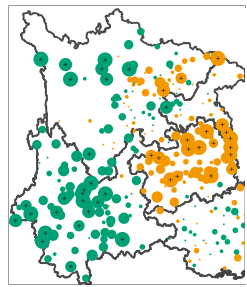

(e) May

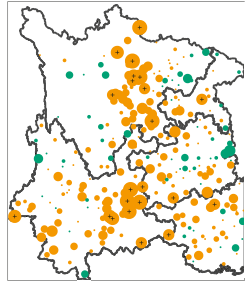

(i) Sep

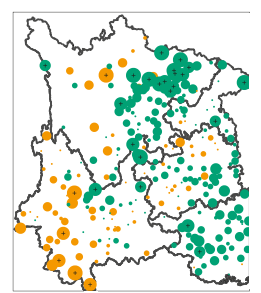

(b) Feb

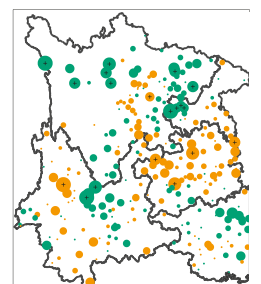

(f) Jun

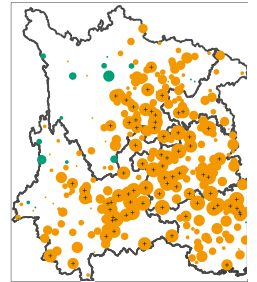

(j) Oct

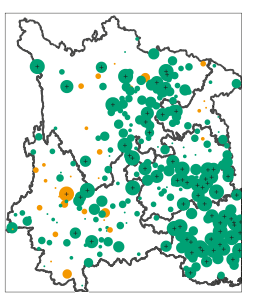

(c) Mar

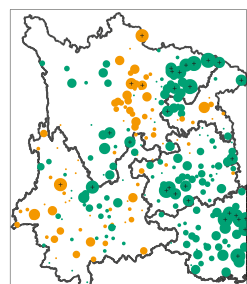

(g) Jul

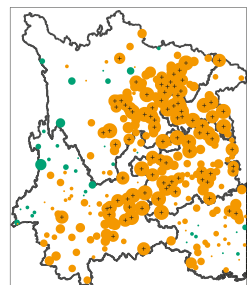

(k) Nov

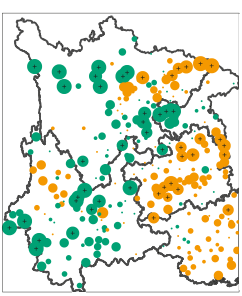

(d) Apr

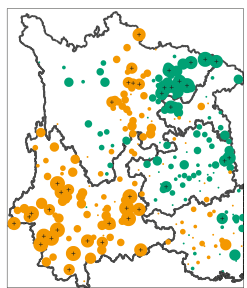

(h) Aug

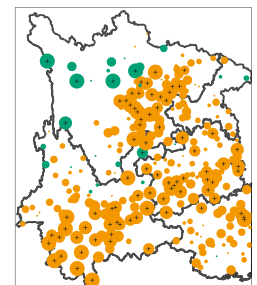

(1) Dec

FIGURE 4: Spatial distributions of monthly $\mathrm{ET}_{0}$ changes during 1961-2012. The plus sign denotes that trend is significant.

changes during October-December have a similar spatial pattern, characterized by negative trends nearly across the whole SWC (excluding northwest part; Figures 4(j)-4(1)), but locations of significant and larger trends $(<-0.015 / \mathrm{yr})$ differ among these months, i.e., in east SC, most of GZ, and east YN in October and November, but in east SC, south GZ, and south YN in December.

\subsection{Spatiotemporal Differences in Dominants of SPEI-3} Dryness/Wetness Changes. With climate change (reflected by precipitation and $\mathrm{ET}_{0}$ ), dry/wet conditions at different temporal (i.e., annual and monthly) and spatial (i.e., regional and site) scales have changed over SWC during 1961-2012 (see Section 3.2). However, SPEI-3 changes exhibit evident differences among study regions (e.g., on annual scale, wetting in wGX but drying in SWC and other four subregions) and months (e.g., for SWC, wetting and drying during February-July and other months, respectively). To that end, we calculated precipitation and $\mathrm{ET}_{0}$ alone contributions to SPEI-3 changes and identified dominants. According to water balance, decreased precipitation and increased $\mathrm{ET}_{0}$ both decrease SPEI-3, namely, drying. Over
SWC and each subregion, annual precipitation and $\mathrm{ET}_{0}$ alone contributions are negative and positive, respectively, indicating that decreased precipitation tends to trigger drying in these regions, but declined $\mathrm{ET}_{0}$ potentially weakens precipitation-induced drying (right for each panel of Figures 5(a1)-5(a6)). Comparing magnitudes of respective contributions from $\mathrm{ET}_{0}$ and precipitation, precipitation plays a determinant role in annual SPEI- 3 changes in SWC, SC, CQ, YN, and GZ, while wGX has dominant of $\mathrm{ET}_{0}$. In left of each panel of Figures 5(a1)-5(a6), monthly $\mathrm{ET}_{0}$ (precipitation) alone contributions show obvious intraannual differences, mainly due to different signs and magnitudes of this factor among 12 months (Figure 2). Based on contributions from precipitation and $\mathrm{ET}_{0}$ alone (Figures 5(a1)-5(a6)), SWC, SC, and CQ (GZ, YN, and wGX) SPEI-3 changes at most of months during JanuaryAugust can be attributed to $\mathrm{ET}_{0}$ (precipitation), while September-December have dominant of precipitation for all regions. Interestingly, YN monthly SPEI-3 changes are always due to precipitation variations (Figure 5(a5)). For wGX (Figure 5(a6)), excluding January, May, and June with dominant of $\mathrm{ET}_{0}$, changed precipitation should be responsible for SPEI-3 changes at other months. 

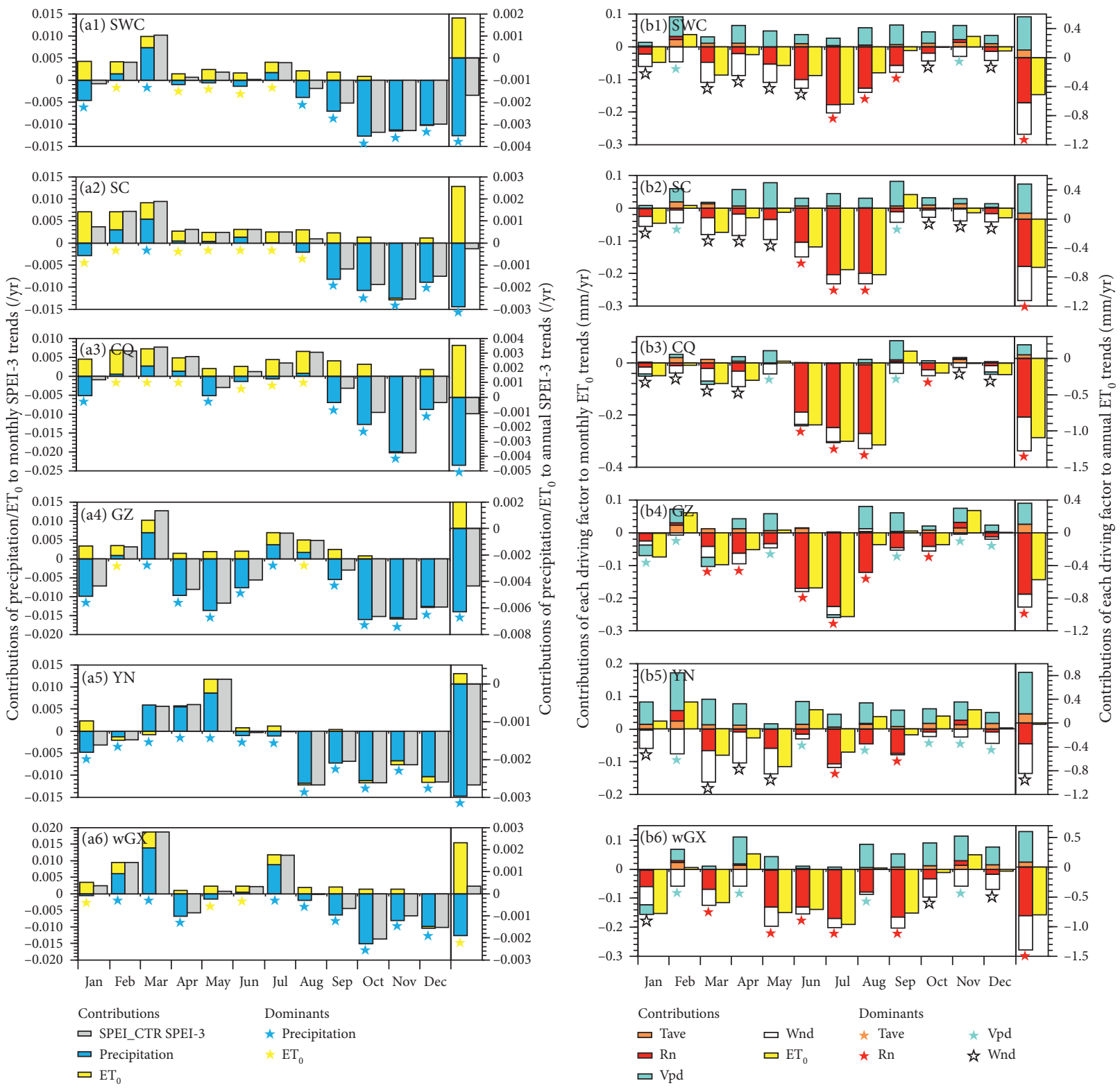

FIGURE 5: Monthly and annual regional mean contributions of precipitation and $\mathrm{ET}_{0}$ alone to SPEI-3 changes (a1-6) and those of the driving factors alone to $\mathrm{ET}_{0}$ trends (b1-6) during 1961-2012. For each panel, left and right $y$ axes show monthly and annual values.

Comparing Figures 3(a1) vs. 3(b1) and Figures 3(a2) vs. 3(b2), SPEI-3 responses at all sites strictly follow concept of SPEI-3 decreasing (increasing) with decreased (increased) precipitation or increased (decreased) $\mathrm{ET}_{0}$. Except for northwest SWC, precipitation negatively contributes to annual SPEI-3 trends in other regions, followed by a larger value $(<-0.009 / \mathrm{yr})$ in southeast SC, most of CQ, north GZ, and mid-east YN (Figure 3(b1)). Figure 3(b2) indicates that negative and positive $\mathrm{ET}_{0}$ contributions generally appear in west SWC and the remaining regions, respectively, of which east and north SC, northeast and west YN, northwest GZ, and mid-east wGX have a larger absolute contribution $(>0.006 / \mathrm{yr})$. In Table 3, site percentage of dominant of precipitation $\left(\mathrm{ET}_{0}\right)$ is $59.0 \%(41.0 \%)$, generally located in southeast SC, south YN, CQ, GZ, and south and northeast
wGX (west and northeast SC, north YN, and middle wGX; Figure 3(b3)).

Based on respective contributions of precipitation (Figures S1(b1-b12)) and $\mathrm{ET}_{0}$ (Figures S2(b1-b12), monthly dominants of SPEI-3 trends are identified at all sites (Figure 6), followed by site percentages with dominants of precipitation and $\mathrm{ET}_{0}$ (Table 3). In January, there is $54.9 \%$ $(45.1 \%)$ of sites with dominant of precipitation $\left(\mathrm{ET}_{0}\right)$, basically located in southeast SC, CQ, GZ, south YN, and northwest wGX (SC except for southeast part, north YN, and wGX excluding southwest part; Figure 6(a)). Relative to January, sites with dominant of $\mathrm{ET}_{0}$ (precipitation) in February obviously increase (decrease) across CQ, YN, and GZ (Figure 6(b)). In March-September, SPEI-3 changes at most of sites (between $64 \%$ and $83 \%$ ) are because of 
TABLE 3: Site percentage (\%) with dominants of changed SPEI-3/ET

\begin{tabular}{|c|c|c|c|c|c|c|c|c|c|c|c|c|c|c|}
\hline & Dominants & Annual & Jan & Feb & Mar & Apr & May & Jun & Jul & Aug & Sep & Oct & Nov & Dec \\
\hline \multirow{2}{*}{ SPEI-3 } & Precipitation & 59.0 & 54.9 & 40.7 & 64.6 & 69.4 & 69.4 & 74.6 & 76.9 & 79.1 & 82.8 & 92.9 & 90.0 & 90.7 \\
\hline & $\mathrm{ET}_{0}$ & 41.0 & 45.1 & 59.3 & 35.4 & 30.6 & 30.6 & 25.4 & 23.1 & 20.9 & 17.2 & 7.1 & 10.0 & 9.3 \\
\hline \multirow{4}{*}{$\mathrm{ET}_{0}$} & Tave & 0 & 0 & 11.2 & 1.1 & 0 & 1.5 & 0.4 & 0 & 0.4 & 0.4 & 2.2 & 3.4 & 1.9 \\
\hline & $\mathrm{Rn}$ & 48.5 & 27.2 & 8.6 & 31.3 & 26.9 & 38.8 & 70.5 & 83.6 & 66.0 & 53.0 & 34.7 & 16.4 & 17.9 \\
\hline & Vpd & 24.6 & 37.7 & 51.5 & 25.0 & 37.3 & 31.7 & 19.8 & 11.9 & 30.2 & 37.3 & 41.4 & 49.6 & 36.6 \\
\hline & Wnd & 26.9 & 35.1 & 28.7 & 42.5 & 35.8 & 28.0 & 9.3 & 4.5 & 3.4 & 9.3 & 21.6 & 30.6 & 43.7 \\
\hline
\end{tabular}

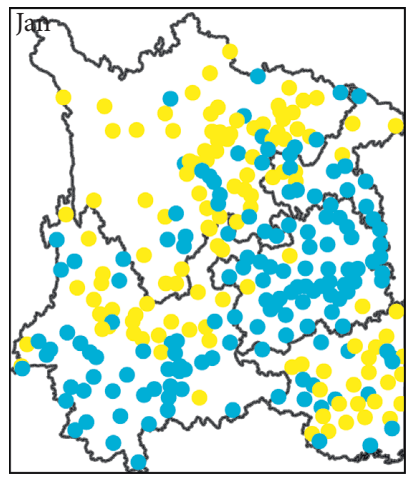

(a)

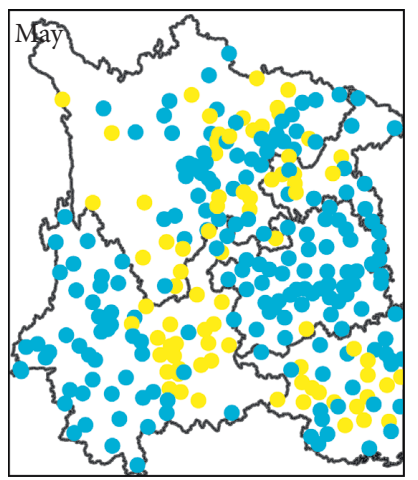

(e)

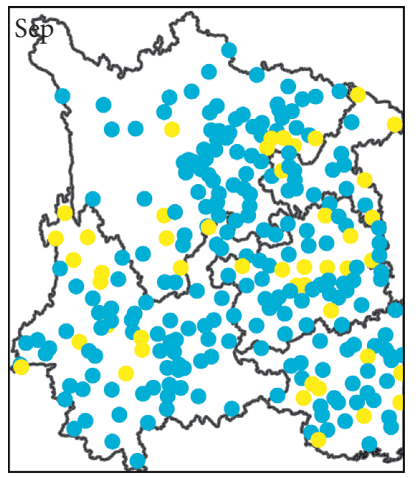

(i)

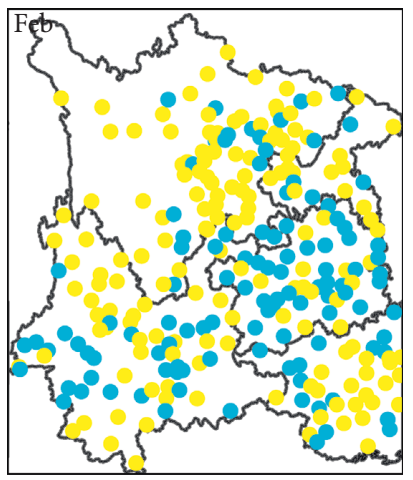

(b)

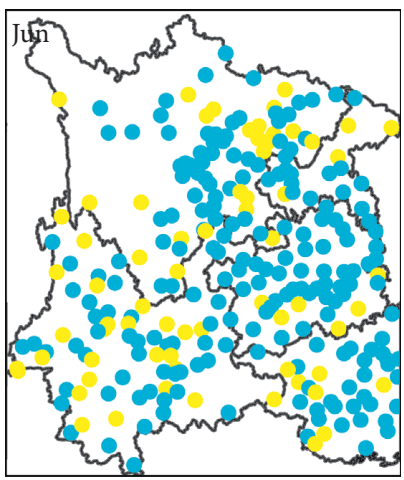

(f)

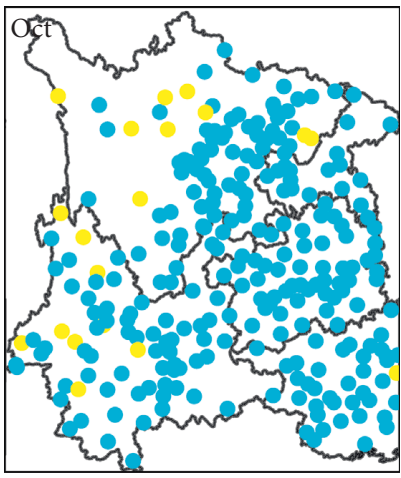

(j)

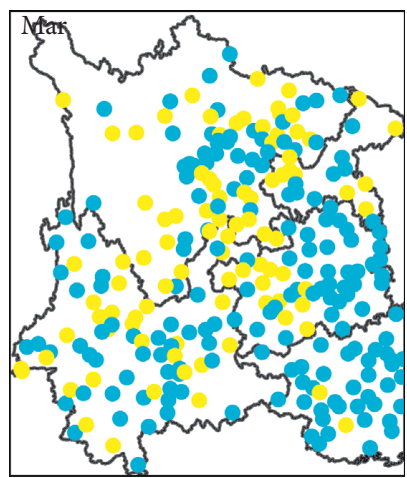

(c)

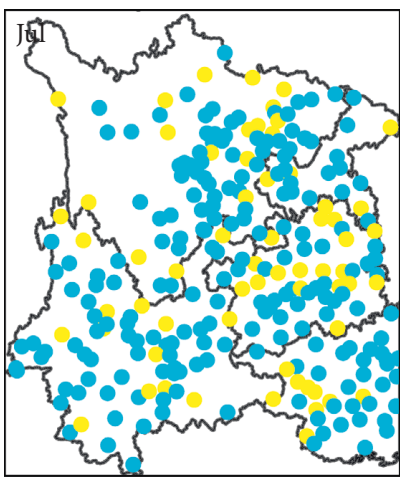

(g)

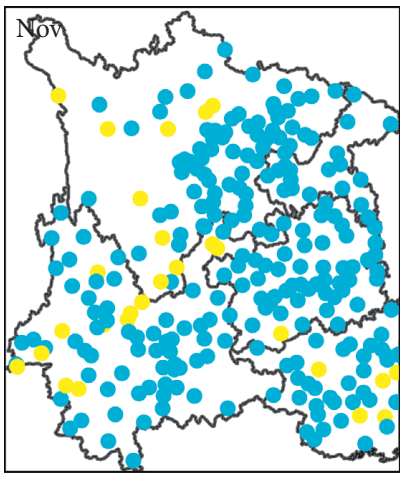

(k)

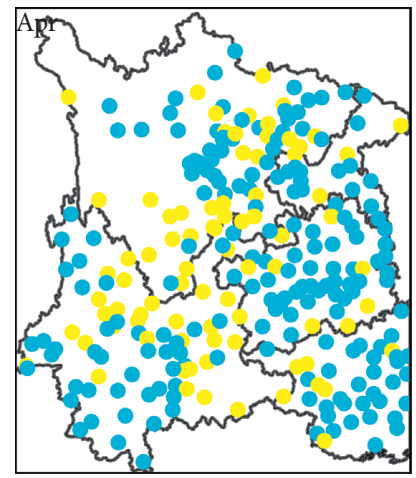

(d)

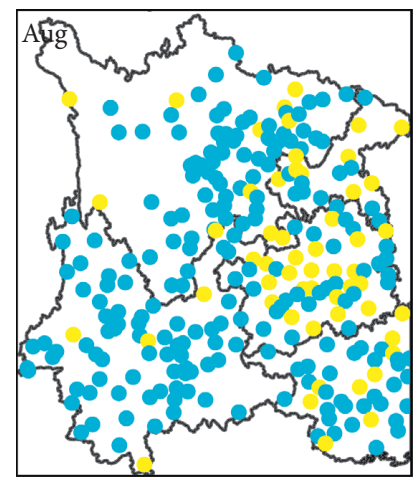

(h)

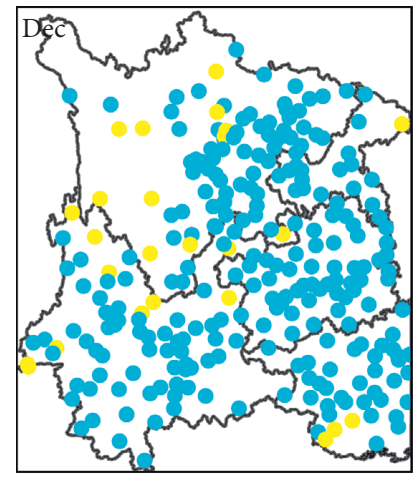

(1)

Dominants

- Precipitation

- $\mathrm{ET}_{0}$

FIgURE 6: Spatial patterns of dominants of monthly SPEI-3 changes during 1961-2012.

precipitation, but with different spatial distributions (Figures 6(c)-6(i)). For example, sites with dominant of precipitation generally concentrate in northeast SWC, east
GZ, YN (excluding mid-north part), and wGX in March (Figure 6(c)), SWC (excluding west SC and east and midnorth YN) in April (Figure 6(d)), north SWC (excluding 
mid-north SC and juncture of SC and CQ), GZ, west YN, and most of wGX in May (Figure 6(e)), and SWC (except for most of GZ) in August (Figure 6(h)). However, in June (Figure 6(f)), July (Figure 6(g)), and September (Figure 6(i)), a wide distribution for dominant of precipitation is detected across SWC. During October-December (Figures 6(k)-6(l)), except for $\leq 10 \%$ of sites with dominant of $\mathrm{ET}_{0}$ mainly located in west SWC, $\geq 90 \%$ of sites have major contributor of precipitation, which approximately spreads throughout SWC. To sum up, dominants of SPEI-3 changes exhibit spatiotemporal differences across SWC, i.e., annual and monthly precipitation for most regions, but $\mathrm{ET}_{0}$ in some regions (e.g., annual SPEI-3 changes in wGX) and sites (e.g., January and February in most of SC and wGX).

\section{Discussions}

4.1. Possible Causes of Changed Precipitation. Numerous researchers generally agreed that with global climate change, regional mean annual precipitation consistently decreased for SWC and its subregions (e.g., SC and YN [44, 51-55]), which coincides with our findings based on an observational dataset at densely distributed sites. However, because of different datasets (i.e., time spans and weather sites) and specifications of the SWC domain, changing rate of precipitation of these studies may differ from ours. To understand recent precipitation variations over SWC, studies have been conducted from perspectives of natural internal variability of climate system, including Arctic Oscillation, North Atlantic Oscillation, Pacific Decadal Oscillation, El Niño-Southern Oscillation, Madden-Julian Oscillation, and sea surface temperatures (SSTs) over west Pacific, Indian, and North Atlantic oceans. For example, based on numerical modellings, Zhang et al. [41] concluded that SWC anomalous precipitation was closely related to location and intensity of the central Pacific El Niño event. Li et al. [56] suggested that North Atlantic SST can significantly and positively impact on boreal spring precipitation over SWC via a North Atlantic-western Russia-western Tibetan Plateau-SWC teleconnection wave train.

Also, external forcings (e.g., greenhouse gases, various aerosols, and solar activities) can influence regional precipitation by a series of complex physical processes and mechanisms [57-59]. Recent findings indicated that elevated greenhouse gas-induced global warming should be partly responsible for annual and monthly precipitation changes [52-54, 60]. Through aerosol-radiation (direct effect) and aerosol-cloud interactions (indirect effect), aerosols can exert a greater impacts on precipitation than greenhouse gases $[57,58]$. Over SWC, a significant decrease in sunshine duration detected on annual scale and at most of months during 1961-2012 (not shown here) may reflect increased aerosols and then change precipitation. As one of the most major energy sources for forcing climate system, any variations of solar activities (e.g., 11-year solar cycle) will be more or less reflected on climate elements [59, 61]. Additionally, precipitation is strongly impacted by topography (more complex terrain over SWC in Figure 1) [53, 54], local evapotranspiration [62-64], and land use/cover change (e.g., urbanization and deforestation) $[65,66]$. More importantly, these influential factors, including natural internal variability of climate system, external forcings, and others, may often be mutually connected through atmospheric circulation and complex physical processes and mechanisms. Therefore, to explore possible explanations of precipitation changes needs to synthetically consider these factors and their linkages.

4.2. Attributing Changed $E T_{0}$. At first, we used the FAO-56 Penman-Monteith equation to perform five experiments (details in Table S1) and then quantified respective impacts from each $\mathrm{ET}_{0}$ driving factor (i.e., Tave, $\mathrm{Rn}, \mathrm{Vpd}$, and $\mathrm{Wnd}$ ) based on the same separation method as equation (4). Lastly, dominants of $\mathrm{ET}_{0}$ changes were identified by comparing contributions of these factors. Regionally, the major contributor of annual $\mathrm{ET}_{0}$ reduction is Wnd in $\mathrm{YN}$ but $\mathrm{Rn}$ in other regions (right of each panel of Figure 5(b1)-5(b6)). For each region, evident differences in dominants of $\mathrm{ET}_{0}$ changes exist among 12 months, i.e., most $(\geq 6)$ of months for SWC, SC, and CQ (GZ and YN) having dominant of Wnd (Vpd), but wGX corresponding to dominants of $\mathrm{Rn}$ and Vpd in five and four months, respectively. As shown in Figure S4(c) and Table 3, annual dominant of Rn concentrates in east SWC and accounts for the largest site percentage of $48.5 \%$, followed by $24.6 \%$ of sites with dominant of Vpd generally located in south SWC and $26.9 \%$ of sites with dominant of Wnd scattered across SWC. In January and April (Table 3), there is a comparable site percentage (around 35\%) between dominants of Vpd and Wnd. For February and November (Table 3), the maximum and the secondary largest site percentages of around $50 \%$ and $30 \%$ correspond to dominants of Vpd and Wnd, respectively. In March (December; Table 3), Wnd as a dominant accounts for $>40 \%$ of sites, but $>30 \%$ of sites have dominant of $\mathrm{Rn}$ $(\mathrm{Vpd})$. During May and October, site percentages of dominants of $\mathrm{Vpd}$ or $\mathrm{Rn}$, and $\mathrm{W}$ nd are respectively $>30 \%$ and $>20 \%$. For June-September, $\mathrm{ET}_{0}$ changes at a half of sites can be attributed to $\mathrm{Rn}$, especially for June and July having a maximum site percentage (>70\%). Interestingly, several and even no sites with dominant of Tave (Table 3) suggest that Tave impacts on $\mathrm{ET}_{0}$ and then dryness/wetness variations are much limited.

Notably, considering major aims of this study and extensive investigations of $\mathrm{ET}_{0}$ driving factors' changes over SWC $[46,67,68]$, we just analyzed dominants of $\mathrm{ET}_{0}$ changes here, but detailed information can be found in supporting materials, including monthly and annual changes in Tave, Rn, Vpd, and Wnd on both regional and site scales (Figures S3, S4(a1-a4), and S5(a1-15), annual and monthly spatial distributions of these factors' contributions to $\mathrm{ET}_{0}$ trends (Figures S4(b1-b4), S5(a5-18), dominants of changed $\mathrm{ET}_{0}$ (Figures S5(a9-19)), and related descriptions in Text S3.

4.3. Uncertainties. In this study, a new separation method was applied to obtain precipitation and $\mathrm{ET}_{0}$ alone contributions to SPEI-3 dryness/wetness changes over SWC 
during 1961-2012, and then attribution analyses are performed; however, there still exist potential uncertainties, which may influence the confidence level of our conclusions. We hereby show some possible sources of uncertainties from several perspectives. The first is Rn estimation. Because of limited sites with solar radiation measurements, $\mathrm{Rn}$ is computed using the semi-physical formulas of Allen et al. [48] (see Text S1) and sunshine duration. It is well known that land surface albedo is a critical parameter for accurately calculating Rn; however, it is set to be 0.23 within this algorithm. Studies have pointed out that land surface albedo exhibits apparent spatial and temporal variations, which are closely associated with climate backgrounds, soil types, soil moisture, land use/cover, and their changes [69-72]. Therefore, unchangeable land surface albedo potentially introduces uncertainties into estimated $\mathrm{Rn}$ and even $\mathrm{ET}_{0}$, and lastly biases SPEI-3. Secondly, vegetation responses to climate change and increased $\mathrm{CO}_{2}$ level are not considered by the FAO-56 Penman-Monteith equation. Mainly because the surface and the leaf stomatal resistance and leaf area index (LAI) are unavailable, the FAO-56 PenmanMonteith equation is proposed based on several hypotheses of a single leaf stomatal resistance of $100 \mathrm{~s} / \mathrm{m}$ under wellwatered conditions, sunlit LAI of $1.44 \mathrm{~m}^{2} / \mathrm{m}^{2}$. and surface resistance of $70 \mathrm{~s} / \mathrm{m}$ [48]. Noteworthily, increasing evidences from observations and modellings have confirmed that several indicators (e.g., stomatal resistance and LAI) of plant structure and physiology have varied with changing climate and increasing $\mathrm{CO}_{2}$ level, in spite of some uncertainties and differences (e.g., magnitude of stomatal resistance and LAI variations) among various plants [73-77]. Then, incomplete considerations of plant responses would like to impact our results and the dryness/wetness-related researches [78]. Thirdly, drought-vegetation interactions are neglected. Under context of drought, vegetation will dramatically alter by controlling stomatal conductance and LAI $[73,74]$; e.g., plant stomata are less open or epicuticular waxes are produced, and thus leaf transpiration decreases. Specially for more severe droughts, a higher vapor pressure gradient between leaves and atmosphere possibly leads to vegetation mortality [79-84]. In reverse, different components (e.g., precipitation received by land surface, ET, and soil moisture losses) of water balance would significantly change because of drought-induced vegetation variations or mortality, and lastly dry/wet conditions varies [64, 85, 86].

In addition, several limitations of this study should be kept in mind. One widely used drought index at a 3-month scale (i.e., SPEI-3) coupled with only the FAO-56 Penman-Monteith equation is employed in this study, and this treatment may potentially influence the universality of our findings, e.g., whether the roles of precipitation and $\mathrm{ET}_{0}$ in dryness/wetness changes are consistent among different drought indices, and for a specific drought index with different potential evapotranspiration formulations. Considering the complex associations of drought with precipitation and $\mathrm{ET}_{0}$, the separated contributions by linear equations (i.e., equation (3)) may introduce some uncertainties into our results, despite the better performance in quantifying the impacts of precipitation and $\mathrm{ET}_{0}$ on SPEI-3 trends. Thus, ignoring the influences from the aforementioned factors may have caused uncertainties in the present study.

\section{Conclusions}

In this study, we firstly investigate precipitation, $\mathrm{ET}_{0}$, and SPEI-3 changes over SWC during 1961-2010 on different spatiotemporal scales. Then, attribution analyses of changed SPEI-3 are conducted based on separated respective contributions from precipitation and $\mathrm{ET}_{0}$. Major results can be summarized below:

(i) Regionally, annual precipitation $\left(\mathrm{ET}_{0}\right)$ changes between $-2.16 \mathrm{~mm} / \mathrm{yr} \quad(-1.09 \mathrm{~mm} / \mathrm{yr})$ and $-0.82 \mathrm{~mm} / \mathrm{yr}(-0.02 \mathrm{~mm} / \mathrm{yr})$ over SWC and its five subregions, which also show declined precipitation $\left(\mathrm{ET}_{0}\right)$ at most of months. Over all regions (except for wGX), annual SPEI-3 slightly decreases, implying that these regions become drying during 1961-2010. Among 12 months, drying and wetting trends for each region generally occur in January and September-December, and the remaining months, respectively.

(ii) Precipitation reduction is major contributor of annual SWC drying during 1961-2012. However, annual dominants of changed SPEI-3 exhibit evident regional differences; e.g., positive (negative) trends in wGX (other four subregions) are due to decreased $\mathrm{ET}_{0}$ (precipitation). There exist 59\% of sites with dominant of precipitation in southeast SC, south YN, CQ, GZ, and south and northeast wGX, while $41 \%$ of sites with dominant of $\mathrm{ET}_{0}$ are located in the remaining regions.

(iii) Major contributors of regional mean SPEI-3 trends indicate obvious intra-annual differences, i.e., SWC, SC, CQ, and GZ with dominant of precipitation $\left(\mathrm{ET}_{0}\right)$ in September-December (most of JanuaryAugust), YN always with the major contributor of precipitation, and wGX with dominant of precipitation $\left(\mathrm{ET}_{0}\right)$ in February-April and JulyDecember (January, May, and June). Moreover, intra-annual differences in dominants also exist at each site.

Based on a full investigation of SPEI-3 changes on different spatiotemporal scales, we confirm that dryness/ wetness has changed across SWC due to climate change during 1961-2012, and major contributors (i.e., precipitation and $\mathrm{ET}_{0}$ ) exhibit evident spatiotemporal differences. These detailed analyses is of significance for deeply understanding spatial-temporal evolutions of dry/wet conditions (e.g., drying) and even droughts (e.g., ongoing and intensifying droughts) over SWC and formulating specific measures to sustain regional development (e.g., water resources, ecosystem, and agriculture). Findings, e.g., higher or comparable impact of $\mathrm{ET}_{0}$ on SPEI-3 than that of precipitation and spatiotemporal differences in dominants of dryness/wetness changes, suggest that role of $\mathrm{ET}_{0}$ and 
spatiotemporal differences in dominants should be involved in drought monitoring and forecasting system. Also, this study provides a reference framework for quantitatively evaluating spatiotemporal dryness/wetness variations with climate change in other regions of the globe, especially for those with significant drying/wetting.

\section{Data Availability}

All the original meteorological observations supporting this article are not available to the public, but they are obtained and used through cooperation with the China Meteorological Administration (CMA). If the readers would like to use this dataset, they can contact National Meteorological Information Center of CMA (http://data.cma.cn/). The generated data and the source codes for the methods in this study are available from the authors upon request (sun.s@ nuist.edu.cn or 20171201132@nuist.edu.cn).

\section{Additional Points}

(i) A full analysis of dryness/wetness changes over Southwest China (SWC) is performed. (ii) To attribute dryness/wetness changes, climate change contributions are quantified. (iii) Dominants of dryness/wetness changes show evident spatiotemporal differences. (iv) This study provides a reference framework to attribute dryness/wetness variation.

\section{Conflicts of Interest}

The authors declare that they have no conflicts of interest.

\section{Acknowledgments}

This work was jointly supported by the National Key Research and Development Program of China (Grant nos. 2018YFC1507101 and 2017YFA0603701), the National Natural Science Foundation of China (Grant nos. 41605042 and 41875094), the Natural Science Foundation of Jiangsu Province, China (Grant no. BK20151525), the Qinglan Project of Jiangsu Province of China, and the Science Technology Department of Zhejiang Province, China (Grant no. LGN18D050001).

\section{Supplementary Materials}

Text S1: Rn estimation. Text S2: spatial distributions of monthly precipitation and $\mathrm{ET}_{0}$ changes. Text $\mathrm{S} 3$ : changes in major driving factors of $\mathrm{ET}_{0}$. Text S4: spatial distributions of dominants of monthly $\mathrm{ET}_{0}$. Figure S1: spatial distributions of monthly precipitation change (a1-a12) and its contribution to SPEI-3 (b1-b12) during 1961-2012. The plus sign in a1-a12 denotes that this trend is significant with $p<0.05$. Figure S2: spatial distributions of monthly $\mathrm{ET}_{0}$ change (a1-a12) and its contribution to SPEI-3 (b1-b12) during 1961-2012. The plus sign in a1-a12 denotes that this trend is significant with $p<0.05$. Figure S3: monthly (right) and annual trends (left) of major driving factors of $\mathrm{ET}_{0}$ from regional series of each subregion and SWC from 1961 to 2012. The asterisk denotes that this trend is significant.
Figure S4: spatial distributions of annual changes in the major $\mathrm{ET}_{0}$ driving factors and their contributions during 1961-2012. The cross in a1-a4 represents that the trend is significant with $p<0.05$. Figure S5: spatial distributions of monthly changes of major driving factors of $\mathrm{ET}_{0}(\mathrm{a} 1-\mathrm{al})$ with their contributions to $\mathrm{ET}_{0}$ changes (a5-al8), and dominants of monthly $\mathrm{ET}_{0}$ (a9-al9). Table S1: detailed information about numerical experiments for attributing $\mathrm{ET}_{0}$ changes. Table S2: site percentage with increased and decreased Tave/Rn/Vpd/Wnd. (Supplementary Materials)

\section{References}

[1] J. Romm, "The next dust bowl," Nature, vol. 478, no. 7370, pp. 450-451, 2011.

[2] D. Wilhite, "Drought as a natural hazard: concepts and definitions," in Drought: A Global Assessment, D. A. Wilhite, Ed., pp. 3-18, Routledge, London, UK, 2000.

[3] A. Dai, K. E. Trenberth, and T. Qian, "A global dataset of palmer drought severity index for 1870-2002: relationship with soil moisture and effects of surface warming," Journal of Hydrometeorology, vol. 5, no. 6, pp. 1117-1130, 2004.

[4] E. Lu, Y. Luo, R. Zhang, Q. Wu, and L. Liu, "Regional atmospheric anomalies responsible for the 2009-2010 severe drought in China," Journal of Geophysical Research, vol. 116, no. D21, 2011.

[5] E. Lu, W. Y. Cai, Z. H. Jiang et al., "The day-to-day monitoring of the 2011 severe drought in China," Climate Dynamics, vol. 43, no. 1-2, pp. 1-9, 2014.

[6] J. Yang, D. Gong, W. Wang, M. Hu, and R. Mao, "Extreme drought event of 2009/2010 over southwestern China," Meteorology and Atmospheric Physics, vol. 115, no. 3-4, pp. 173-184, 2012.

[7] L. Wang and W. Chen, "A CIMP5 multimodel projection of future temperature, precipitation and climatological drought in China," International Journal of Climatology, vol. 34, no. 6, pp. 2059-2078, 2014.

[8] L. Wang, W. Chen, and W. Zhou, "Assessment of future drought in Southwest China based on CMIP5 multimodel projections," Advances in Atmospheric Sciences, vol. 31, no. 5, pp. 1035-1050, 2014.

[9] L. Wang, W. Chen, W. Zhou, and G. Huang, "Understanding and detecting super extreme droughts in Southwest China through an integrated approach and index," Quarterly Journal of the Royal Meteorological Society, vol. 142, no. 694, pp. 529-535, 2016.

[10] W. C. Palmer, Meteorological Droughts, U.S. Department of Commerce, Weather Bureau Research Paper 45, Washington, DC, USA, 1965.

[11] T. B. McKee, N. J. Doesken, and J. Kleist, “The relationship of drought frequency and duration to time scales," in Proceedings of the Eighth Conference on Applied Climatology, pp. 179-184, American Meteorological Society, Anaheim, CA, USA, 1993.

[12] S. M. Vicente-Serrano, S. Beguería, and J. López-Moreno, “A multiscalar drought index sensitive to global warming: the standardized precipitation evapotranspiration index," Journal of Climate, vol. 23, no. 7, pp. 1696-1718, 2010.

[13] J. S. Feng, H. Y. Wang, X. T. Wang et al., "The application of relative humidity index to agricultural drought monitoring," Journal of Applied Meteorology Science, vol. 22, no. 6, pp. 766-772, 2011. 
[14] A. Dai, "Characteristics and trends in various forms of the palmer drought severity index during 1900-2008," Journal of Geophysical Research, vol. 116, no. D12, 2011.

[15] J. Sheffield, E. F. Wood, and M. L. Roderick, "Little change in global drought over the past 60 years," Nature, vol. 491, no. 7424, pp. 435-438, 2012.

[16] M. T. Hobbins, A. Dai, M. L. Roderick, and G. D. Farquhar, "Revisiting the parameterization of potential evaporation as a driver of long-term water balance trends," Geophysical Research Letters, vol. 35, no. 12, 2008.

[17] S. Sun, H. Chen, W. Ju et al., "On the coupling between precipitation and potential evapotranspiration: contributions to decadal drought anomalies in the Southwest China," Climate Dynamics, vol. 48, no. 11-12, pp. 3779-3797, 2017.

[18] A. AghaKouchak, L. Cheng, O. Mazdiyasni, and A. Farahmand, "Global warming and changes in risk of concurrent climate extremes: insights from the 2014 California drought," Geophysical Research Letters, vol. 41, no. 24, pp. 8847-8852, 2014.

[19] S. Shukla, M. Safeeq, A. AghaKouchak, K. Guan, and C. Funk, "Temperature impacts on the water year 2014 drought in California," Geophysical Research Letters, vol. 42, no. 11, pp. 4384-4393, 2015.

[20] A. P. Williams, R. Seager, J. T. Abatzoglou, B. I. Cook, J. E. Smerdon, and E. R. Cook, "Contribution of anthropogenic warming to California drought during 2012-2014," Geophysical Research Letters, vol. 42, no. 16, pp. 6819-6828, 2015.

[21] T. R. McVicar, M. L. Roderick, R. J. Donohue et al., "Global review and synthesis of trends in observed terrestrial nearsurface wind speeds: implications for evaporation," Journal of Hydrology, vol. 416-417, pp. 182-205, 2012.

[22] L. Wang, W. Chen, W. Zhou, and G. Huang, “Teleconnected influence of tropical Northwest Pacific sea surface temperature on interannual variability of autumn precipitation in Southwest China," Climate Dynamics, vol. 45, no. 9-10, pp. 2527-2539, 2015.

[23] M. P. Byrne and P. A. O'Gorman, “Understanding decreases in land relative humidity with global warming: conceptual model and GCM simulations," Journal of Climate, vol. 29, no. 24, pp. 9045-9061, 2016.

[24] A. J. Simmons, P. Berrisford, D. P. Dee, H. Hersbach, S. Hirahara, and J.-N. Thépaut, "A reassessment of temperature variations and trends from global reanalyses and monthly surface climatological datasets," Quarterly Journal of the Royal Meteorological Society, vol. 143, no. 702, pp. 101-119, 2017.

[25] K. Wang and R. E. Dickinson, "A review of global terrestrial evapotranspiration: observation, modeling, climatology, and climatic variability," Reviews of Geophysics, vol. 50, no. 2, 2012.

[26] X. Liu and D. Zhang, "Trend analysis of reference evapotranspiration in Northwest China: the roles of changing wind speed and surface air temperature," Hydrological Processes, vol. 27, no. 26, pp. 3941-3948, 2013.

[27] D. Zhang, X. Liu, Q. Zhang, K. Liang, and C. Liu, "Investigation of factors affecting intra-annual variability of evapotranspiration and streamflow under different climate conditions," Journal of Hydrology, vol. 543, pp. 759-769, 2016.

[28] A. J. Teuling, A. F. Van Loon, S. I. Seneviratne et al., "Evapotranspiration amplifies European summer drought," Geophysical Research Letters, vol. 40, no. 10, pp. 2071-2075, 2013.
[29] A. Dai, "Increasing drought under global warming in observations and models," Nature Climate Change, vol. 3, no. 1, pp. 52-58, 2013.

[30] K. E. Trenberth, A. Dai, G. van der Schrier et al., "Global warming and changes in drought," Nature Climate Change, vol. 4, no. 1, pp. 17-22, 2014.

[31] D. J. McEvoy, J. H. L. Huntington, J. F. Mejia, and M. T. Hobbins, "Improved seasonal drought forecasts using reference evapotranspiration anomalies," Geophysical Research Letters, vol. 43, no. 1, pp. 377-385, 2016.

[32] M. Yu, Q. Li, M. J. Hayes, M. D. Svoboda, and R. R. Heim, "Are droughts becoming more frequent or severe in China based on the standardized precipitation evapotranspiration index: 1951-2010?," International Journal of Climatology, vol. 34, no. 3, pp. 545-558, 2014.

[33] D. Wang, B. Zhang, M.-L. An, T.-F. Zhang, D.-M. Ji, and P.-G. Ren, "Temporal and spatial distributions of drought Southwest China over the past 53 years based on standardized precipitation evapotranspiration index," Journal of Natural Resources, vol. 29, no. 6, pp. 1003-1016, 2014.

[34] H. Wang, Y. Chen, and Y. Pan, "Characteristics of drought in the arid region of northwestern China," Climate Research, vol. 62 , no. 2, pp. 99-113, 2015.

[35] W. Lou, S. Sun, K. Sun, X. Yang, and S. Li, "Summer drought index using SPEI based on 10-day temperature and precipitation data and its application in Zhejiang Province (Southeast China)," Stochastic Environmental Research and Risk Assessment, vol. 31, no. 10, pp. 2499-2512, 2017.

[36] L. Wang and W. Chen, "Characteristics of multi-timescale variabilities of the drought over last 100 years in Southwest China," Advances in Meteorological Science and Technology, vol. 2, no. 4, pp. 21-26, 2012.

[37] M. Liu, X. Xu, A. Y. Sun, and K. Wang, "Decreasing spatial variability of drought in southwest China during 1959-2013," International Journal of Climatology, vol. 37, no. 13, 2017.

[38] J. Qiu, "China drought highlights future climate threats," Nature, vol. 465, no. 7295, pp. 142-143, 2010.

[39] Y. Li, H. Xu, and D. Liu, "Features of the extremely severe drought in the east of Southwest China and anomalies of atmospheric circulation in summer 2006," Acta Meteorologica Sinica, vol. 25, no. 2, pp. 176-187, 2011.

[40] D. Barriopedro, C. M. Gouveia, R. M. Trigo, and L. Wang, "The 2009/10 drought in China: possible causes and impacts on vegetation," Journal of Hydrometeorology, vol. 13, no. 4, pp. 1251-1267, 2012.

[41] W. Zhang, F.-F. Jin, J. X., L. Qi, H.-L. Ren, and H. L. Ren, "The possible influence of a nonconventional El Niño on the severe autumn drought of 2009 in southwest China," Journal of Climate, vol. 26, no. 21, pp. 8392-8405, 2013.

[42] W. Zhang, F.-F. Jin, and A. Turner, "Increasing autumn drought over southern China associated with ENSO regime shift," Geophysical Research Letters, vol. 41, no. 11, pp. 4020-4026, 2014.

[43] N. S. Diffenbaugh, D. L. Swain, and D. Touma, "Anthropogenic warming has increased drought risk in California," Proceedings of the National Academy of Sciences of the United States of America, vol. 112, no. 13, pp. 3931-3936, 2015.

[44] N. Qin, X. Chen, G. Fu, J. Zhai, and X. Xue, "Precipitation and temperature trends for the Southwest China: 1960-2007," Hydrological Processes, vol. 24, no. 25, pp. 3733-3744, 2010.

[45] X. Yang, Z. Li, Q. Feng et al., "The decreasing wind speed in Southwestern China during 1969-2009, and possible causes," Quaternary International, vol. 263, pp. 71-84, 2012. 
[46] Z.-X. Fan and A. Thomas, "Spatiotemporal variability of reference evapotranspiration and its contributing climatic factors in Yunnan Province, SW China, 1961-2004," Climatic Change, vol. 116, no. 2, pp. 309-325, 2013.

[47] S. Sun, H. Chen, W. Ju, M. Yu, W. Hua, and Y. Yin, "On the attribution of the changing hydrological cycle in Poyang Lake Basin, China," Journal of Hydrology, vol. 514, pp. 214-225, 2014.

[48] R. G. Allen, L. S. Pereira, D. Raes, and M. Smith, Crop Evapotranspiration-Guidelines for Computing Crop Water Requirements, Food and Agriculture Organization of the United Nations, FAO Irrigation and Drainage Paper 56, Rome, Italy, 1998.

[49] D. Zhang, X. Liu, and H. Hong, "Assessing the effect of climate change on reference evapotranspiration in China," Stochastic Environmental Research and Risk Assessment, vol. 27, no. 8, pp. 1871-1881, 2013.

[50] T. Liu, L. Li, J. Lai, C. Liu, and W. Zhuang, "Reference evapotranspiration change and its sensitivity to climate variables in southwest China," Theoretical and Applied Climatology, vol. 125, no. 3-4, pp. 499-508, 2016.

[51] J. Huang, S. Sun, Y. Xue, J. Li, and J. Zhang, "Spatial and temporal variability of precipitation and dryness/wetness during 1961-2008 in Sichuan Province, West China," Water Resources Management, vol. 28, no. 6, pp. 1655-1670, 2014.

[52] B. Liu, C. Chen, Y. Lian, J. Chen, and X. Chen, "Long-term change of wet and dry climatic conditions in the southwest karst area of China," Global and Planetary Change, vol. 127, pp. 1-11, 2015.

[53] B. Liu, Y. Li, J. Chen, and X. Chen, "Long-term change in precipitation structure over the karst area of Southwest China," International Journal of Climatology, vol. 36, no. 6, pp. 2417-2434, 2016.

[54] M. Liu, X. Xu, and A. Sun, "Decreasing spatial variability in precipitation extremes in southwestern China and the local/ large-scale influencing factors," Journal of Meteorological Research, vol. 120, no. 13, pp. 6840-6488, 2015.

[55] C. Zhang, Q. Tang, D. Chen, L. Li, X. Liu, and H. Cui, "Tracing changes in atmospheric moisture supply to the drying Southwest China," Atmospheric Chemistry and Physics, vol. 17, no. 17, pp. 10383-10393, 2017.

[56] G. Li, J. Chen, X. Wang et al., "Remote impact of North Atlantic sea surface temperature on rainfall in southwestern China during boreal spring," Climate Dynamics, vol. 50, no. 1-2, pp. 541-553, 2018.

[57] M. A. Bollasina, Y. Ming, and V. Ramaswamy, "Anthropogenic aerosols and the weakening of the south Asian summer monsoon," Science, vol. 334, no. 6055, pp. 502-505, 2011.

[58] H. Liao, W. Chang, and Y. Yang, "Climatic effects of air pollutants over China: a review," Advances in Atmospheric Sciences, vol. 32, no. 1, pp. 115-139, 2015.

[59] L. Zhao, J. Wang, H. Liu, and Z. Xiao, "Amplification of the solar signal in the summer monsoon rainband in China by synergistic actions of different dynamical responses," Journal of Meteorological Research, vol. 31, no. 1, pp. 61-72, 2017.

[60] P. Shi, M. Wu, S. Qu et al., "Spatial distribution and temporal trends in precipitation concentration indices for the Southwest China," Water Resources Management, vol. 29, no. 11, pp. 3941-3955, 2015.

[61] H. Chen, H. Ma, X. Li, and S. Sun, "Solar influences on spatial patterns of Eurasian winter temperature and atmospheric general circulation anomalies," Journal of Geophysical Research: Atmospheres, vol. 120, no. 17, pp. 8642-8657, 2015.
[62] Y. Huang and X. Cui, "Moisture sources of torrential rainfall events in the Sichuan basin of China during summers of 2009-13," Journal of Hydrometeorology, vol. 16, no. 4, pp. 1906-1917, 2015.

[63] L. Li, A. J. Dolman, and Z. Xu, "Atmospheric moisture sources, paths, and the quantitative importance to the Eastern Asian Monsoon Region," Journal of Hydrometeorology, vol. 17, no. 2, pp. 637-649, 2016.

[64] M. Zhang, N. Liu, R. Harper et al., "A global review on hydrological responses to forest change across multiple spatial scales: importance of scale, climate, forest type and hydrological regime," Journal of Hydrology, vol. 546, pp. 44-59, 2017.

[65] H. Chen, Y. Zhang, M. Yu et al., "Large-scale urbanization effects on eastern Asian summer monsoon circulation and climate," Climate Dynamics, vol. 47, no. 1-2, pp. 117-136, 2015.

[66] N. Devaraju, G. Bala, and A. Modak, "Effects of large-scale deforestation on precipitation in the monsoon regions: remote versus local effects," Proceedings of the National Academy of Sciences of the United States of America, vol. 112, no. 11, pp. 3257-3262, 2015.

[67] X. Dong, B. Xi, and P. Minnis, "Observational evidence of changes in water vapor, clouds, and radiation at the ARM SGP site," Geophysical Research Letters, vol. 33, no. 19, pp. 730732, 2006.

[68] X. Zheng, W. M. Kang, T. L. Zhao, Y. X. Luo, C. C. Duan, and J. Chen, "Long-term trends in sunshine duration over yunnan-guizhou plateau in southwest China for 1961-2005," Geophysical Research Letters, vol. 35, no. 15, 2008.

[69] S. Liang, A. H. Strahler, and C. Wathall, "Retrieval of land surface albedo from satellite observations: a simulation study," Journal of Applied Meteorology and Climatology, vol. 38, no. 6, pp. 712-725, 1999.

[70] M. Mira, M. Weiss, F. Baret et al., "The MODIS (collection V006) BRDF/albedo product MCD43D: temporal course evaluated over agricultural landscape," Remote Sensing of Environment, vol. 170, pp. 216-228, 2015.

[71] G. L. Stephens, D. O’rien, P. J. Webster, P. Pilewski, S. Kato, and J.-L. Li, "The albedo of earth," Reviews of Geophysics, vol. 53, no. 1, pp. 141-163, 2015.

[72] M. V. Saha, P. D’Odorico, and T. M. Scanlon, “Albedo changes after fire as an explanation of fire-induced rainfall suppression," Geophysical Research Letters, vol. 44, no. 8, pp. 3916-3923, 2017.

[73] U. Feller, "Drought stress and carbon assimilation in a warming climate: reversible and irreversible impacts," Journal of Plant Physiology, vol. 203, pp. 84-94, 2016.

[74] S. B. Gray and S. M. Brady, "Plant developmental responses to climate change," Developmental Biology, vol. 419, no. 1, pp. 64-77, 2016.

[75] Z. Xu, Y. Jiang, B. Jia, and G. Zhou, "Elevated $-\mathrm{CO}_{2}$ response of stomata and its dependence on environmental factors," Frontiers in Plant Science, vol. 7, 2016.

[76] A. Paschalis, G. G. Katul, S. Fatichi, S. Palmroth, and D. Way, "On the variability of the ecosystem response to elevated atmospheric $\mathrm{CO}_{2}$ across spatial and temporal scales at the duke forest FACE experiment," Agricultural and Forest Meteorology, vol. 232, pp. 367-383, 2017.

[77] S. L. Voelker, M. C. Stambaugh, J. Renée Brooks, F. C. Meinzer, B. Lachenbruch, and R. P. Guyette, "Evidence that higher $\left[\mathrm{CO}_{2}\right]$ increases tree growth sensitivity to temperature: a comparison of modern and paleo oaks," Oecologia, vol. 183, no. 4, pp. 1183-1195, 2017. 
[78] P. C. D. Milly and K. A. Dunne, "Potential evapotranspiration and continental drying," Nature Climate Change, vol. 6, no. 10, pp. 946-949, 2016.

[79] C. D. Allen, A. K. Macalady, H. Chenchouni et al., "A global overview of drought and heat-induced tree mortality reveals emerging climate change risks for forests," Forest Ecology and Management, vol. 259, no. 4, pp. 660-684, 2010.

[80] P. A. Stott, D. A. Stone, and M. R. Allen, "Human contribution to the European heatwave of 2003," Nature, vol. 432, no. 7017 , pp. $610-614,2004$

[81] H. Duan, J. S. Amthor, R. A. Duursma, A. P. O’Grady, B. Choat, and D. T. Tissue, "Carbon dynamics of eucalypt seedlings exposed to progressive drought in elevated $\left[\mathrm{CO}_{2}\right]$ and elevated temperature," Tree Physiology, vol. 33, no. 8, pp. 779-792, 2013.

[82] G. Gea-Izquierdo, B. Viguera, M. Cabrera, and I. Cañellas, "Drought induced decline could portend widespread pine mortality at the xeric ecotone in managed mediterranean pine-oak woodlands," Forest Ecology and Management, vol. 320 , pp. 70-82, 2014.

[83] D. J. N. Young, J. T. Stevens, J. M. Earles et al., "Long-term climate and competition explain forest mortality patterns under extreme drought," Ecology Letters, vol. 20, no. 1, pp. 78-86, 2017.

[84] Y. Liu, A. J. Parolari, M. Kumar, C. W. Huang, G. G. Katul, and A. Porporato, "Increasing atmospheric humidity and $\mathrm{CO}_{2}$ concentration alleviate forest mortality risk," Proceedings of the National Academy of Sciences of the United States of America, vol. 114, no. 37, pp. 9918-9923, 2017.

[85] A. J. Teuling, S. I. Seneviratne, R. Stöckli et al., "Contrasting response of European forest and grassland energy exchange to heatwaves," Nature Geoscience, vol. 3, no. 10, pp. 722-727, 2010.

[86] Y. Yang, T. R. McVicar, R. J. Donohue et al., "Lags in hydrologic recovery following an extreme drought: assessing the roles of climate and catchment characteristics," Water Resources Research, vol. 53, no. 6, pp. 4821-4837, 2017. 

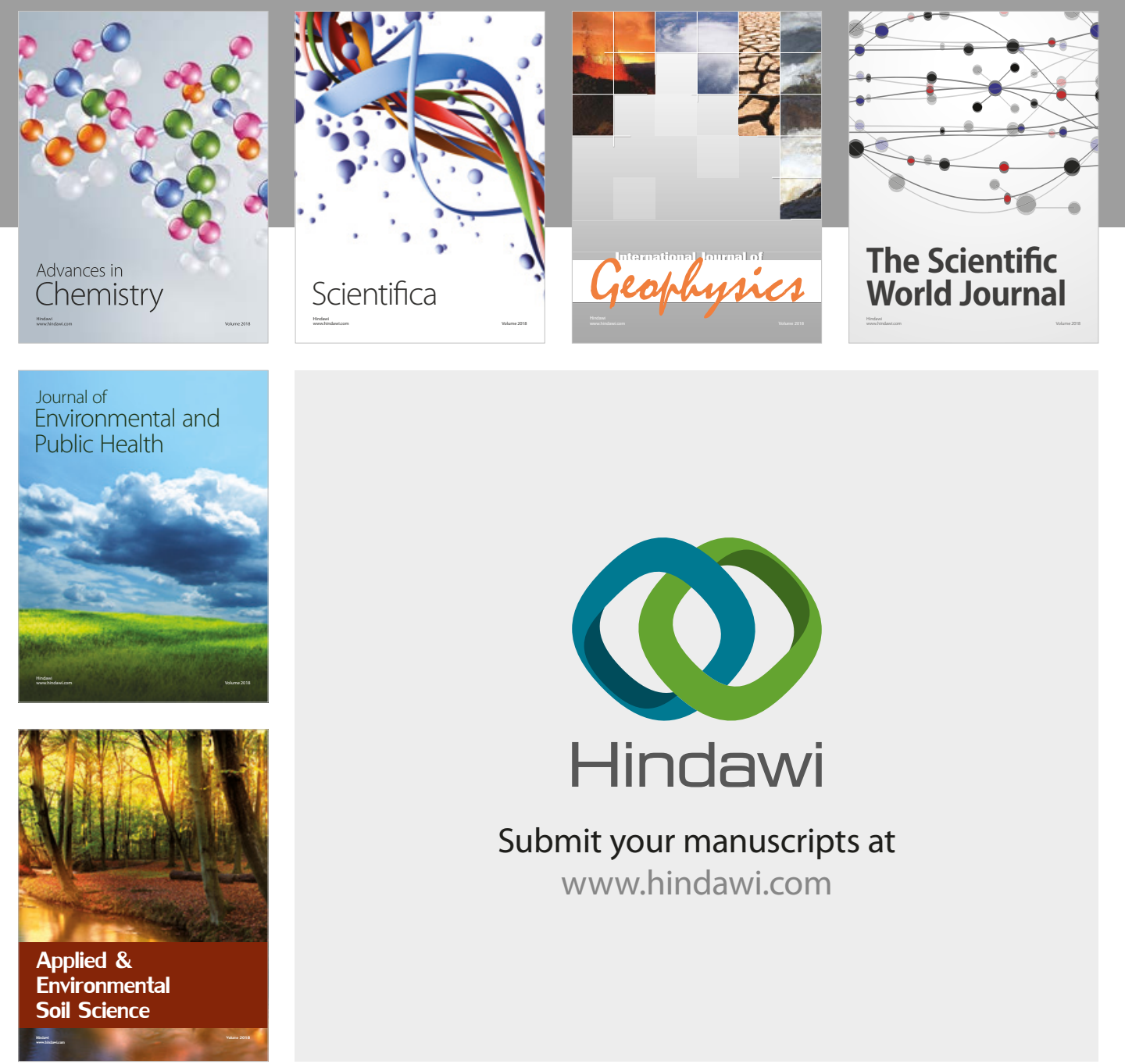

The Scientific

\section{World Journal}
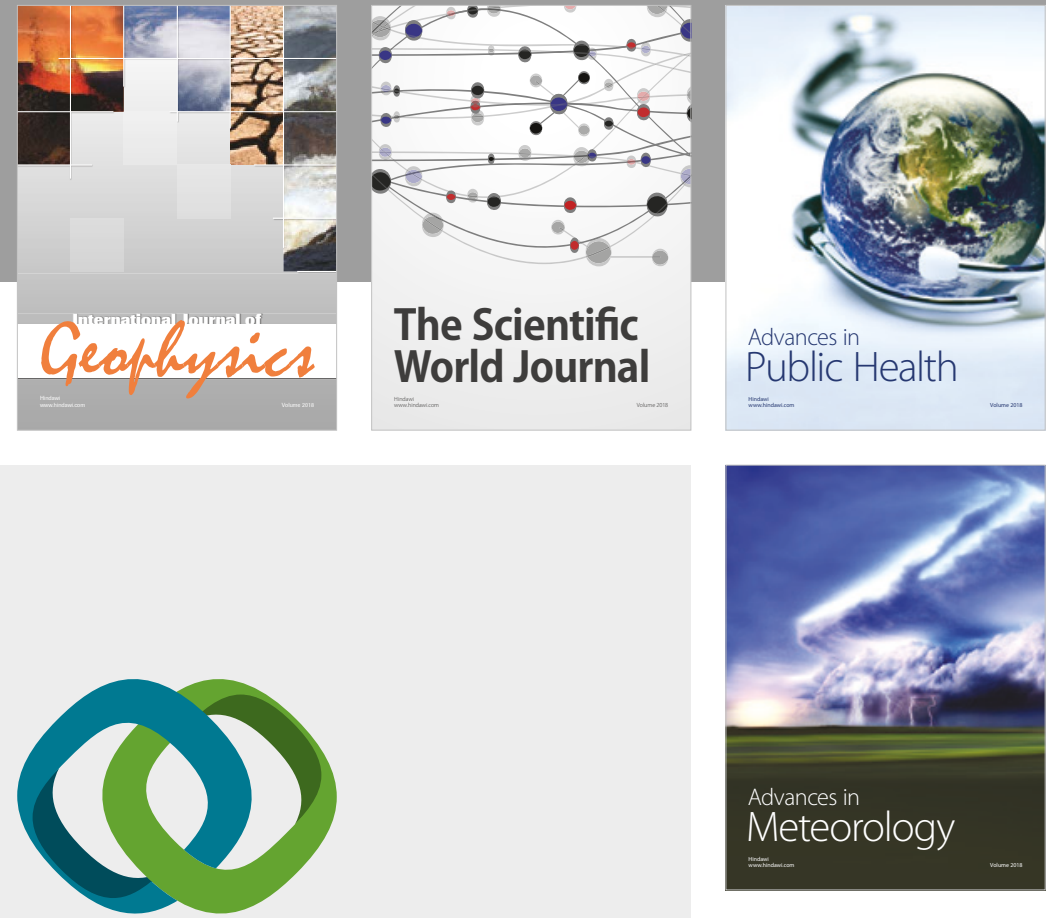

Advan

Public Health

\section{Hindawi}

Submit your manuscripts at

www.hindawi.com
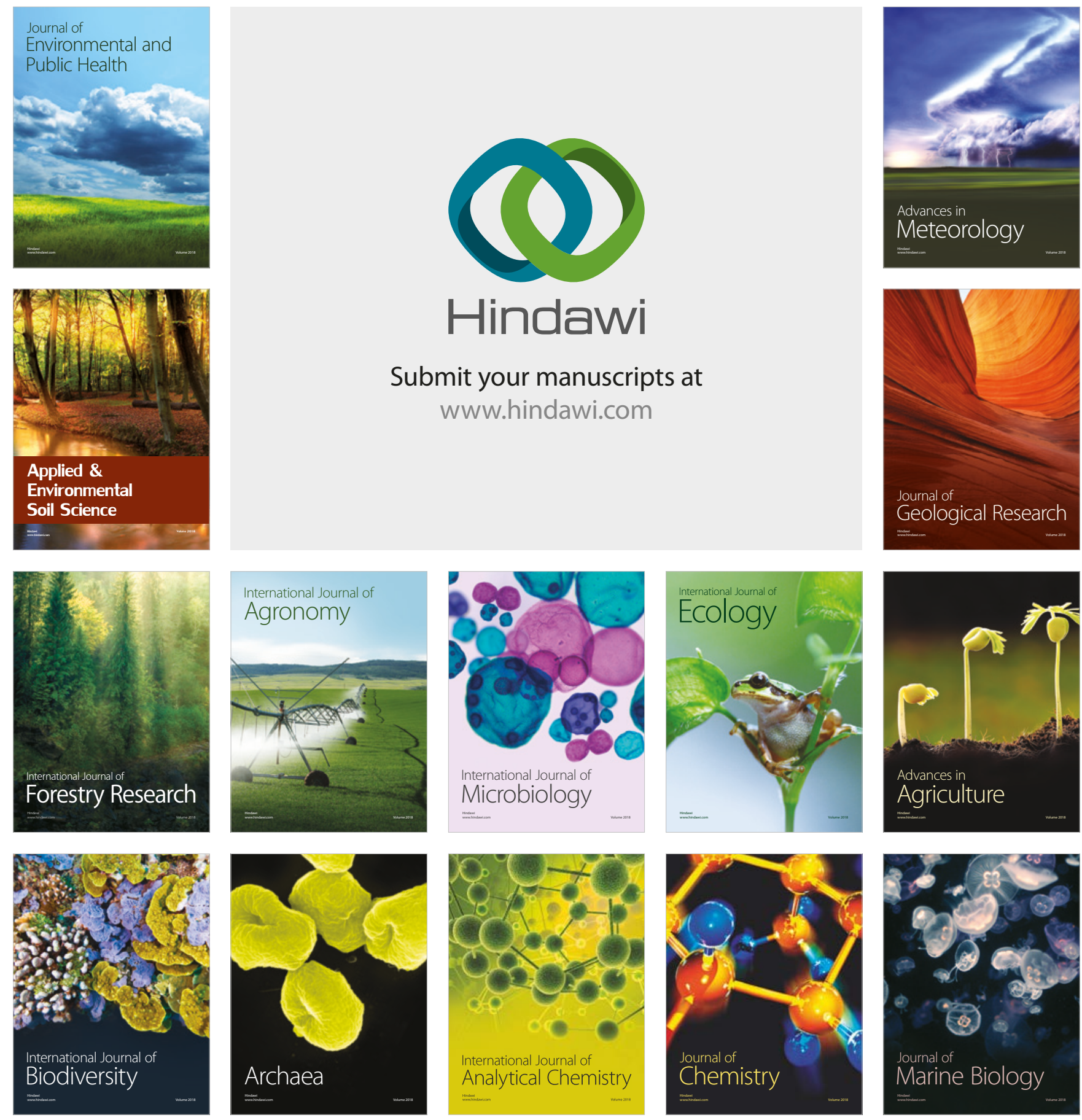